\title{
Reclutamiento forzado de niños y niñas (abduction) en el conflicto armado colombiano: los menores de 18 años como víctimas con protección especial reforzada en el DIH y DIDH*
}

\begin{abstract}
Forced Recruitment of Children (Abduction) in the Colombian Armed Conflict: Under 18 Years of Age as Victims with Special Protection Reinforced in IHL and IHRL
\end{abstract}

Yadira Elena Alarcón-Palacio ${ }^{\text {a }}$

Pontificia Universidad Javeriana, Colombia

yalarcon@javeriana.edu.co

ORCID: http://orcid.org/0000-0002-8635-6264
DOI: https://doi.org/10.11144/Javeriana.vj138.rfnn Redalyc: http://www.redalyc.org/articulo.oa $? \mathrm{id}=82559799002$

Fecha de recepción: 30 Julio 2018 Fecha de aprobación: 30 Noviembre 2018 Fecha de publicación: 30 Mayo 2019

\section{Resumen:}

Se trabaja el problema de los niños soldados, víctimas del reclutamiento forzado. Con revisión del tratamiento de los niños en la guerra en el Derecho Internacional Humanitario (DIH) y en el Derecho Internacional de los Derechos Humanos (DIDH) con énfasis en la edad de protección en los instrumentos internacionales. Se analiza el reclutamiento forzado en las normas internas como causa del Estado de cosas inconstitucional por desplazamiento forzado, para llegar al problema de los niños soldados de la guerrilla de las Fuerzas Armadas Revolucionarias de Colombia - Ejército del Pueblo, FARC-EP y su tratamiento en la implementación del Acuerdo de Paz. Se concluye que, en la discusión de la edad, la Corte Constitucional asume una solución ambigua al dar prevalencia a normas internacionales posteriores a garantías constitucionales que ya se tenían en el derecho interno. Colombia tiene una deuda pendiente con su infancia perdida.

Palabras clave: Reclutamiento forzado, abduction, conflicto armado, niños víctimas, protección reforzada, niños soldados, infancia.

\section{Abstract:}

This paper addresses the child soldiers issue, as victims of forced recruitment. A review of the treatment of children in war in International Humanitarian Law (IHL) and in International Human Rights Law (IHRL) with emphasis on the age of protection in international instruments is carried out. The forced recruitment in the internal norms is analyzed as the cause of the unconstitutional state of affairs due to forced displacement, which leads to the problem of the soldier children of the guerrilla Revolutionary Armed Forces of Colombia - People's Army [Fuerzas Armadas Revolucionarias de Colombia - Ejército del Pueblo, FARC-EP] and their treatment in the implementation of the Peace Agreement. It is concluded that in the discussion of age, the Constitutional Court adopts an ambiguous solution when giving precedence to international norms subsequent to constitutional guarantees that already had in the domestic law. Colombia has an outstanding debt with their lost childhood.

Keywords: Forced recruitment, abduction, armed conflict, child victims, reinforced protection, child soldiers, childhood.

\section{Introducción. El problema de los niños en el conflicto armado colombiano}

Para poder abordar el problema de los niños en el conflicto armado colombiano, es importante señalar primero cuál es el concepto de un niño soldado. Un niño soldado, según indica el Protocolo Facultativo sobre la participación de los niños en la guerra, es "cualquier persona menor de 18 años que forma parte de cualquier tipo de fuerza armada regular o irregular en cualquier capacidad, inclusive, pero no solo, como cocinero, porteador, mensajero, y cualquiera que acompaña a estos grupos, excepto los familiares. La definición incluye niñas reclutadas para realizar actividades sexuales y contraer matrimonios por la fuerza". Por tanto, "niño

Notas de autor: 
soldado" no solamente se refiere a un niño o a una niña que porta o ha portado armas. La definición es intencionalmente amplia para que la protección abarque a la mayor cantidad posible de niños, y para asegurar su inclusión en los programas de desmovilización y reintegración ${ }^{1}$. La expresión "niño soldado" también alcanza a "toda persona menor de 18 años que es miembro o está vinculado a las fuerzas armadas gubernamentales o a cualquier grupo armado regular o irregular, en lugares donde exista o no un conflicto armado" $^{2}$.

Con esto se puede decir que los niños que se consideran soldados en Colombia son todas aquellas personas menores de 18 años que forman o han formado parte de cualquier tipo de fuerza armada, se trate del ejército o de grupos armados al margen de la ley; hayan o no portado armas y con indiferencia de las labores que realicen o de las actividades a las que sean o hayan sido sometidas dentro de estos grupos.

Según el FONDO DE LAS NACIONES UNIDAS PARA LA INFANCIA, UNICEF, los niños utilizados como soldados pierden su infancia y son víctimas a menudo de una extrema brutalidad. Hay numerosos casos en que los grupos armados han drogado a estos niños antes de enviarlos al combate, y los han obligado a cometer atrocidades contra sus propias familias a fin de destruir sus lazos familiares y comunitarios. Las niñas tienen que participar a menudo en actividades sexuales, por lo general, al servicio de un comandante, pero a veces son víctimas de violaciones en grupo ${ }^{3}$.

Según el Informe Graça Machel, una de las tendencias más alarmantes en los conflictos armados es la participación de los niños como soldados. Los niños integran ejércitos en los que desempeñan funciones de apoyo, como cocineros, cargadores, mensajeros y espías. Sin embargo, cada vez se observa más que los adultos incorporan a los niños soldados deliberadamente. Algunos comandantes han observado la conveniencia de utilizar a los niños soldado porque son "más obedientes, no cuestionan las órdenes y son más fáciles de manipular que los soldados adultos" ${ }^{4}$.

El movimiento de rechazo a la participación de los niños en la guerra data de mediados del siglo XX. Muchos instrumentos internacionales se han ocupado de regular tanto el derecho a la guerra como el derecho en la guerra, y todos han sido insuficientes para frenar la participación de los niños en los conflictos bélicos.

La situación que ocurre en Colombia en cuanto a la participación de los niños en el conflicto bélico y su impacto en la niñez colombiana en aspectos de orden psicosocial, fue fruto de un análisis de una investigación cuyos fines eran cuantificar algunos efectos de los hechos victimizantes a que estaban sometidos los niños, y avanzar en la comprensión de esos impactos en el desarrollo y funcionamiento psicosocial de quienes son víctimas de reclutamiento ilícito, desplazamiento forzado, orfandad por conflicto armado, violencia sexual en el marco del conflicto, minas antipersona, desaparición forzada y secuestro. Esta investigación dio vida al documento Impacto del conflicto armado en el estado psicosocial de niños, niñas y adolescentes, realizado por el Instituto Colombiano de Bienestar Familiar (en adelante, ICBF), con el apoyo de la Organización Internacional para las Migraciones (en adelante, OIM) y el Fondo de las Naciones Unidas para la Infancia (en adelante, UNICEF).

El estudio sostiene:

A pesar de que la participación de niños en el conflicto se encuentra regulada por leyes de injerencia internacional como la Convención sobre los Derechos de los Niños, el Protocolo Facultativo de la Convención sobre los Derechos del Niño relativo a la participación en los conflictos armados, el Estatuto de Roma o los Principios de París, se estima que cerca de 300.000 niños menores de 18 años participan activamente en conflictos armados en el mundo (Unicef, 2013) y de estos, 120.000 se encuentran en el continente africano (Morini, 2010). La participación directa de los niños en el conflicto ha sido considerada desde 1999 una de las peores formas de trabajo infantil (International Labour Organization, ILO, 1999), pues en el conflicto los niños, niñas y adolescentes no solo operan como combatientes, mensajeros, porteadores o cocineros, sino que también deben desempeñarse como servidores sexuales (Unicef, 2012), en muchas ocasiones, perdiendo entre todas estas labores la esencia de la niñez y la oportunidad de gozar de un mejor futuro, ya que en primer lugar interrumpen su proceso escolar y su proyecto de vida se transforma considerablemente ${ }^{5}$.

Así mismo, el estudio destaca: 
El ICBF ha atendido a 5619 niños y niñas durante el período del 16 de noviembre de 1999 al 30 de septiembre de 2012. De acuerdo con la Secretaría Técnica de la Comisión Intersectorial, el 90\% de los niños atendidos por el ICBF afirman haber estado vinculados a un grupo armado con otros niños y niñas. Algunas investigaciones muestran que las FARC y el ELN [Ejército de Liberación Nacional] son los principales autores del alistamiento, reclutamiento y utilización de niños en el conflicto interno colombiano. Algunas de las funciones que desempeñan los niños son mensajería, vigilancia, raspado de hojas de coca, transporte de drogas ilícitas y reclutamiento de otros jóvenes (Rueda, 2010; Watchlist on Children and Armed Conflict, Watchlist, 2012). En el estudio realizado por la OIM y el ICBF (2013a) se encontró que, en la muestra estudiada de niños, niñas y adolescentes desvinculados, la mayoría pertenecieron a las FARC-EP y su permanencia fue de un año. La actividad de mayor frecuencia dentro del grupo fue la cocina, seguido de hacer oficios y llevar mensajes. En menor proporción otras actividades fueron ayudar en cultivos ilícitos, organizar reuniones y cuidar prisioneros. El reclutamiento de niños en Colombia no siempre ha estado acompañado de hechos violentos como la amenaza directa o la intimidación a la comunidad. La propaganda política en comunidades, el ofrecimiento de salarios, de comida y protección (Asamblea General de las Naciones Unidas, 2011) y el uso de otros niños para atraer a sus compañeros (Watchlist on Children and Armed Conflict, Watchlist, 2012) han sido otras de las estrategias empleadas por estos grupos para mantener y avanzar en sus operaciones militares de forma económica (Watchlist on Children and Armed Conflict Watchlist, 2012). La mayoría de los niños, niñas y adolescentes son reclutados de forma forzada no solo por las facilidades para persuadirlos y constreñirlos a cometer delitos, sino por la evidente facilidad que tienen de utilizar armas ligeras y de pequeño tamaño respecto a los adultos (Morini, 2010; Morisseau, 2004; Unicef, 2006). El reclutamiento forzado de niños, niñas y adolescentes, y, en general, los hechos que caracterizan el conflicto interno colombiano han desembocado en el desplazamiento de comunidades que huyen, entre otras cosas, de la muerte de sus hijos y familiares ${ }^{6}$.

Se destaca que, cuando un niño, niña o adolescente es reclutado por los grupos armados, también cambia su entorno, pero en este caso lo lleva en ocasiones a verse a sí mismo como agresor y no como víctima y esto le genera grandes cantidades de culpa ${ }^{7}$.

Quizás lo más explícito de este informe sobre la verdadera dimensión del drama de la niñez en Colombia se refleja en la investigación en cuanto a los datos relativos a la atención de niños y niñas desvinculados del conflicto armado que se han registrado en los programas de desmovilización del ICBF y su relación con los grupos al margen de la ley de los que provienen.

El estudio sostiene:

En relación con los datos correspondientes a los niños, niñas y adolescentes desvinculados del conflicto armado, el ICBF atendió 5252 niños, niñas y adolescentes desvinculados de los grupos armados ilegales entre noviembre de 1999 y enero del año 2013. Los niños, niñas y adolescentes que se han desmovilizado vienen con mayor frecuencia de las FARC. En cuanto a los bloques o frentes que reclutan más menores de edad, a juzgar por el número de niños, niñas y adolescentes desvinculados provenientes de los mismos, están los siguientes:

Por las AUC: al sur de Casanare, 175; Vencedores de Arauca, 51; Central Bolívar, Santa Rosa del Sur, 67; Cacique Nutibara, 51, y Centauros, 79.

Por las Farc: Frente 21, 104; Frente 48, 129; Frente 6, 86, Frente 49, 74; Frente 47, 69; Frente 40, 66; Frente 34, 59; Frente 32, 100; Frente 29, 79; Frente 27, 53; Frente 18, 61; Frente 16, 60; Frente 14, 65; Frente 15, 70; Frente 10, 52, y Frente 1, 66. Los departamentos con tasas superiores a 100 niños, niñas y adolescentes reclutados por 100.000 habitantes menores de edad son Caquetá (225 por 100.000), Vaupés (184 por 100.000), Guaviare (174 por 100.000), Putumayo (146 por 100.000), Arauca (144 por 100.000), Meta (124 por 100.000), Casanare (115 por 100.000) y Guainía (100 por 100.000). En cuanto a la edad de reclutamiento de niños, niñas y adolescentes, el promedio fue de 13,5 años y la misma estuvo entre los 0 y los 17 años. El grupo de edad de niños, niñas y adolescentes muy pequeños. Esto se debe a que nacieron dentro de los grupos armados. En cuanto a las características de estos niños, niñas y adolescentes se encontró que en la actualidad los niños, niñas y jóvenes tienen entre 11 y 32 años de edad. La edad promedio de desvinculación de los niños, niñas y adolescentes es de 17 años. El rango oscila entre los 9 y los 18 años. El 28\% de los desvinculados fueron niñas y el 72\%, niños. El departamento en el cual nacieron más niños, niñas y adolescentes de los grupos armados al margen de la ley fueron Antioquia, seguido por Caquetá, Meta y Tolima ${ }^{8}$.

Los niños, niñas y adolescentes muestran unas características particulares según el grupo en el que fueron reclutados.

En el caso de las AUC [Autodefensas Unidas de Colombia]: Los niños, niñas y adolescentes desvinculados de las AUC reciben con menor frecuencia atención familiar, se desvincularon con mayor frecuencia ante el gobierno central, son atendidos por servicios en hogar gestor y hogar tutor con mayor frecuencia, su tiempo de desvinculación es mayor comparado con otros grupos y su desvinculación es menos voluntaria y más por entrega. Igualmente, la tendencia es que muestran una escolaridad más alta al compararlos con los niños, niñas y adolescentes desvinculados de otros grupos. 
En el caso de las bacrim [bandas criminales]: Los niños, niñas y adolescentes desvinculados de las bacrim permanecen por mayor tiempo en los programas del ICBF, tienen menor atención familiar, la etnia indígena es menor en proporción y reciben menos servicios de hogar transitorio que otros.

En el caso del ELN: Con frecuencia, los niños, niñas y adolescentes desvinculados del ELN son de sexo femenino, tienen menor escolaridad que los demás, pertenecen a minorías (afrocolombianos e indígenas) y la autoridad judicial que sigue sus casos es la Fiscalía.

En el caso de las Farc: Los niños, niñas y adolescentes desvinculados de las Farc son con mayor frecuencia de sexo masculino, tienen una escolaridad más alta, han permanecido mayor tiempo en el grupo armado, algunos son afrodescendientes y su desvinculación ha sido más reciente. Igualmente, existe una tendencia mayor a recibir servicios en los Centros de Atención Especializada y a que su desvinculación haya sido voluntaria ${ }^{9}$.

\section{Tratamiento de los niños en la guerra en el Derecho Internacional Humanitario y el Derecho Internacional de los Derechos Humanos}

\section{Evolución de los instrumentos internacionales}

El movimiento en defensa de los derechos de los niños y niñas ha sido una constante en el ámbito internacional como consecuencia de las guerras mundiales ${ }^{10}$. Por el impacto de la Primera Guerra Mundial, la V Asamblea de la Liga de las Naciones aprobó en 1924 la llamada Declaración de Ginebra; esta declaración contenía cinco principios muy genéricos: 1 . El derecho a un desarrollo moral, físico y mental. 2. La alimentación de los niños hambrientos. 3. El cuidado de los niños enfermos. 4. La resocialización de los niños marginados. 5. El cuidado de los niños abandonados o huérfanos. Como principios generales establecía también: la preferencia asistencial en caso de desastre, la prohibición de explotación y la educación conforme a sus cualidades ${ }^{11}$.

En 1948 se produjo la Declaración Universal de los Derechos Humanos, considerada el primer instrumento jurídico internacional general de derechos humanos proclamado por una organización internacional de carácter universal ${ }^{12}$. Este documento marcó un hito en la historia de los derechos humanos. "Elaborada por representantes de todas las regiones del mundo con diferentes antecedentes jurídicos y culturales, la Declaración fue proclamada por la Asamblea General de las Naciones Unidas en París, el 10 de diciembre de 1948 en su resolución 217 A (III) como un ideal común para todos los pueblos y naciones" ${ }^{13}$. La declaración señala en el artículo 25.2 que: "la maternidad y la infancia tienen derecho a cuidados y asistencia especiales. Todos los niños, nacidos de matrimonio o fuera de matrimonio tienen derecho a igual protección social".

Las reglas del DIH se encuentran en una serie de tratados internacionales agrupados en los cuatro Convenios de Ginebra de 1949 y los protocolos I y II adicionales a los Convenios de Ginebra de 1977. En el panorama global, la aparición de los instrumentos internacionales que hacen alusión a los conflictos armados internos puede ubicarse específicamente en el artículo 3, común a los Convenios de Ginebra, y el protocolo II $^{14}$. Señala MARCELA ARELLANO-VELASCO, la protección especial a los niños civiles en tiempo de conflicto armado está ampliamente recogida en el Derecho Internacional; concretamente, 25 artículos del IV Convenio de Ginebra y de los protocolos I y II adicionales a los Convenios de Ginebra se refieren a la protección especial del niño y establecen, entre otros derechos, la evacuación de los niños de zonas de conflicto, su recepción en países neutrales, las obligaciones de los Estados de aceptar la ayuda humanitaria destinada a mujeres embarazadas y niños menores de 15 años, el derecho del niño a beneficiarse de zonas seguras para refugiados, el derecho a que la potencia ocupante facilite a los niños de los territorios ocupados asistencia y educación, el derecho a que se les proteja de cualquier atentado contra el pudor, a que se les proporcionen los cuidados y la ayuda que necesiten, a la reunificación familiar, y a no ser reclutado de manera forzosa u obligatoria antes de la edad de 15 años, entre otros ${ }^{15}$. 
El efecto de la Segunda Guerra Mundial y el desarrollo de las Naciones Unidas condujeron luego a una Segunda Declaración de los Derechos del Niño, proclamada por la Asamblea General de las Naciones Unidas el 20 de noviembre de 1959, que desarrollaba un poco más el contenido de la anterior, en diez principios: la igualdad; el superior interés del niño; la identidad y la nacionalidad; la salud y la seguridad social; el especial tratamiento de los impedidos o disminuidos; el desarrollo pleno y armonioso en el ámbito familiar; la educación; la preferencia en caso de desastre; la prohibición de la explotación; y la protección contra la discriminación ${ }^{16}$.

Los conflictos internos se ven revestidos de un instrumento internacional de aplicación concreta a través del Protocolo II adicional a los Convenios de Ginebra de 1949 relativo a la protección de las víctimas de los conflictos armados sin carácter internacional, del 8 de junio de 1977; este documento internacional conforme a su artículo 1 desarrolla y completa el artículo 3, común a los Convenios de Ginebra del 12 de agosto de 1949, sin modificar sus actuales condiciones de aplicación, se aplicará a todos los conflictos armados que no estén cubiertos por el artículo 1 del Protocolo adicional a los Convenios de Ginebra del 12 de agosto de 1949 relativo a la protección de las víctimas de los conflictos armados internacionales (Protocolo I) y que se desarrollen en el territorio de una Alta Parte contratante entre sus fuerzas armadas y fuerzas armadas disidentes o grupos armados organizados que, bajo la dirección de un mando responsable, ejerzan sobre una parte de dicho territorio un control tal que les permita realizar operaciones militares sostenidas y concertadas y aplicar el presente Protocolo. El Título II relativo al Trato Humano, respecto de las garantías fundamentales, se detiene en el derecho de los niños y señala en su numeral 3:

Se proporcionarán a los niños los cuidados y la ayuda que necesiten y, en particular: a) recibirán una educación, incluida la educación religiosa o moral, conforme a los deseos de los padres o, a falta de estos, de las personas que tengan la guarda de ellos; b) se tomarán las medidas oportunas para facilitar la reunión de las familias temporalmente separadas; c) los niños menores de quince años no serán reclutados en las fuerzas o grupos armados y no se permitirá que participen en las hostilidades 17 ; d) la protección especial prevista en este artículo para los niños menores de quince años seguirá aplicándose a ellos si, no obstante las disposiciones del apartado c), han participado directamente en las hostilidades y han sido capturados; e) se tomarán medidas, si procede, y siempre que sea posible con el consentimiento de los padres o de las personas que, en virtud de la ley o la costumbre, tengan en primer lugar la guarda de ellos, para trasladar temporalmente a los niños de la zona en que tengan lugar las hostilidades a una zona del país más segura y para que vayan acompañados de personas que velen por su seguridad y bienestar ${ }^{18}$.

En 1989 se produjo un hito en el panorama de la defensa internacional de los derechos de los niños. Los derechos de la infancia están plenamente estipulados en la Convención sobre los Derechos del Niño. Elaborada durante 10 años con las aportaciones de representantes de diversas sociedades, culturas y religiones, la Convención fue aprobada como tratado internacional de derechos humanos el 20 de noviembre de $1989^{19}$ . En lo relativo a la participación y utilización de los niños en los conflictos armados, la Convención de 1989 hace referencia específica en los artículos 38 y 39 que al respecto señalan:

Artículo 38. 1. Los Estados Partes se comprometen a respetar y velar por que se respeten las normas del Derecho Internacional Humanitario que les sean aplicables en los conflictos armados y que sean pertinentes para el niño. 2. Los Estados Partes adoptarán todas las medidas posibles para asegurar que las personas que aún no hayan cumplido los 15 años de edad no participen directamente en las hostilidades. 3. Los Estados Partes se abstendrán de reclutar en las fuerzas armadas a las personas que no hayan cumplido los 15 años de edad. Si reclutan personas que hayan cumplido 15 años, pero que sean menores de 18, los Estados Partes procurarán dar prioridad a los de más edad ${ }^{20}$. 4. De conformidad con las obligaciones dimanadas del Derecho Internacional Humanitario de proteger a la población civil durante los conflictos armados, los Estados Partes adoptarán todas las medidas posibles para asegurar la protección y el cuidado de los niños afectados por un conflicto armado.

Artículo 39. Los Estados Partes adoptarán todas las medidas apropiadas para promover la recuperación física y psicológica y la reintegración social de todo niño víctima de: cualquier forma de abandono, explotación o abuso; tortura u otra forma de tratos o penas crueles, inhumanas o degradantes; o conflictos armados. Esa recuperación y reintegración se llevarán a cabo en un ambiente que fomente la salud, el respeto de sí mismo y la dignidad del niño ${ }^{21}$. 
Esta redacción fue objeto de críticas y de comentarios de insatisfacción, ya que no establece una clara prohibición de la participación de los niños en los conflictos bélicos.

\section{La edad de protección en los instrumentos internacionales}

Uno de los factores que cobran relevancia cuando hablamos de la participación o no de los niños y niñas en la guerra es su edad. Si bien parece innecesario hablar de cuál es la edad en la que no deben participar, pues la premisa debería ser que los menores de edad nunca deberían participar en un conflicto de armas ${ }^{22}$; es cierto que, tanto en el panorama internacional como en el panorama nacional colombiano, la edad ha sido objeto de atención de los organismos internacionales y nacionales. Hemos visto cómo se ha venido trabajando el tema de la edad en los instrumentos internacionales y más adelante, veremos cómo estos han sido revisados y asumidos por el Estado colombiano en el marco de la implementación del Acuerdo de Paz con las FARC, lo que puede ser determinante a la hora de establecer la condición de víctimas de los niños que directa o indirectamente participaron de las hostilidades.

Siguiendo con nuestra visión cronológica, ya en 1996 en el Informe Graça Machel, se dimensionaba la problemática de los niños soldados y su edad de reclutamiento. Al respecto, se señalaba que los niños soldados se reclutan de muchas maneras distintas. Algunos se incorporan a la fuerza, otros mediante patrullas de reclutamiento o secuestro y otros se ven obligados a integrar ejércitos armados para defender a sus propias familias. Los gobiernos de unos pocos países reclutan legalmente a los niños menores de 18 años; aunque la edad mínima legal sea 18 años, esa ley no es necesariamente una salvaguardia. En muchos países, los registros civiles son deficientes o simplemente no existen y los niños no saben qué edad tienen. Las personas encargadas del reclutamiento solo pueden adivinar la edad de los niños sobre la base de su desarrollo físico y tal vez consignan en los registros que el niño tiene 18 años para dar la impresión de que están cumpliendo con las leyes nacionales ${ }^{23}$.

En 1998, se expidió el Estatuto de la Corte Penal Internacional, llamado el Estatuto de Roma de la Corte Penal Internacional; en él se consagra en particular la inclusión entre los crímenes de guerra en conflictos armados, tanto internacionales como no internacionales, el reclutamiento o alistamiento de niños menores de 15 años o su utilización para participar activamente en las hostilidades ${ }^{24}$.

A su vez, en 1999, se produjo la Convención sobre las Peores Formas de Trabajo Infantil y la Acción Inmediata para su Eliminación, de la Organización Internacional del Trabajo, OIT, que en su artículo 3 reza:

A los efectos del presente Convenio, la expresión "las peores formas de trabajo infantil" abarca:

a) todas las formas de esclavitud o las prácticas análogas a la esclavitud, como la venta y la trata de niños, la servidumbre por deudas y la condición de siervo, y el trabajo forzoso u obligatorio, incluido el reclutamiento forzoso u obligatorio de niños para utilizarlos en conflictos armados;

b) la utilización, el reclutamiento o la oferta de niños para la prostitución, la producción de pornografía o actuaciones pornográficas;

c) la utilización, el reclutamiento o la oferta de niños para la realización de actividades ilícitas, en particular la producción y el tráfico de estupefacientes, tal como se definen en los tratados internacionales pertinentes, $y$

d) el trabajo que, por su naturaleza o por las condiciones en que se lleva a cabo, es probable que dañe la salud, la seguridad o la moralidad de los niños 25 .

En 2002, entraron en vigencia dos Protocolos Facultativos de la Convención sobre los Derechos del Niño que fueron aprobados por la Asamblea General de las Naciones Unidas el 25 de mayo de 2000. Se trata del Protocolo Facultativo relativo a la venta de niños, la prostitución infantil y la utilización de niños en la pornografía, que entró en vigor el 18 de enero de 2002, y el Protocolo Facultativo relativo a la participación de los niños en los conflictos armados, que entró en vigor el 12 de febrero de $2002^{26}$. 
Respecto a este último, el proceso para adoptarlo fue largo y complicado, el grupo de trabajo se reunió durante seis períodos de sesiones, desde octubre de 1994 hasta enero de 2000, fecha en que finalmente se adoptó el proyecto. Esta dilación en las negociaciones se debió a la dificultad de llegar a un consenso en varios aspectos de la prohibición, como la edad límite, el tipo de participación (directa o indirecta), el tipo de reclutamiento (forzoso o voluntario), y las medidas que habrían de tomar los Estados Partes para prevenir el reclutamiento de niños por los grupos armados no gubernamentales ${ }^{27}$.

Todo en consideración a que el artículo 1 de la Convención sobre los Derechos del Niño precisa que, para los efectos de esa Convención, se entiende por niño todo ser humano menor de 18 años de edad, salvo que, en virtud de la ley que le sea aplicable, haya alcanzado antes la mayoría de edad. Y en sus consideraciones se agrega el convencimiento de que un Protocolo Facultativo de la Convención por el que se eleve la edad mínima para el posible reclutamiento de personas en las fuerzas armadas y su participación en las hostilidades contribuirá eficazmente a la aplicación del principio de que el interés superior del niño ha de ser una consideración primordial en todas las decisiones que le conciernan.

A pesar de las deficiencias y limitaciones que se le señalan, este Protocolo supuso un notable avance en relación con las normas existentes hasta la fecha, en especial con respecto al artículo 38 de la Convención sobre los Derechos del Niño, en uno de los aspectos de mayor controversia, es decir, en el relativo a la edad de participación de los niños en los conflictos armados. Con este Protocolo se logra elevar la edad a 18 años para la participación de los niños y se evita de ese modo que menores de esa edad puedan verse involucrados en las hostilidades; todo ello basado en el Principio del Interés Superior del niño, uno de los principios fundamentales de la Convención sobre los Derechos del Niño ${ }^{28}$.

Uno de los puntos específicos del debate en torno a la edad de reclutamiento para la participación en las hostilidades es su naturaleza voluntaria o forzosa. El consenso en torno a poner los 18 años como límite para el reclutamiento forzado era prácticamente generalizado. En cambio, hubo muchos pronunciamientos en la defensa de la permisividad para la participación voluntaria de menores de 18 años, fundadas esencialmente en las condiciones económicas de muchos estados y en la estabilidad laboral que proporcionan las fuerzas $\operatorname{armadas}^{29}$.

Finalmente, las decisiones adoptadas que cabe destacar en el Protocolo Facultativo relativo a la participación de los niños en los conflictos armados en las fuerzas armadas estatales son las siguientes:

Artículo 1. Los Estados Partes adoptarán todas las medidas posibles para que ningún miembro de sus fuerzas armadas menor de 18 años participe directamente en hostilidades.

Artículo 2. Los Estados Partes velarán por que no se reclute obligatoriamente en sus fuerzas armadas a ningún menor de 18 años.

Artículo 3. 1. Los Estados Partes elevarán la edad mínima, contada en años, para el reclutamiento voluntario de personas en sus fuerzas armadas nacionales por encima de la fijada en el párrafo 3 del artículo 38 de la Convención sobre los Derechos del Niño, teniendo en cuenta los principios formulados en dicho artículo, y reconociendo que en virtud de esa Convención los menores de 18 años tienen derecho a una protección especial. 2. Cada Estado Parte depositará, al ratificar el presente Protocolo o adherirse a él, una declaración vinculante en la que se establezca la edad mínima en que permitirá el reclutamiento voluntario en sus fuerzas armadas nacionales y se ofrezca una descripción de las salvaguardias que haya adoptado para asegurarse de que no se realiza ese reclutamiento por la fuerza o por coacción. 3. Los Estados Partes que permitan el reclutamiento voluntario en sus fuerzas armadas nacionales de menores de 18 años establecerán medidas de salvaguardia que garanticen, como mínimo, que: a) Ese reclutamiento sea auténticamente voluntario; b) Ese reclutamiento se realice con el consentimiento informado de los padres o de quienes tengan la custodia legal; c) Esos menores estén plenamente informados de los deberes que supone ese servicio militar; d) Esos menores presenten pruebas fiables de su edad antes de ser aceptados en el servicio militar nacional.

Como puede verse, quedó una relativa permisividad de reclutamiento voluntario en las fuerzas armadas de los Estados Parte antes de los 18 años con algunas condiciones.

Ahora bien, en cuanto a la participación de los niños en los grupos armados distintos a las fuerzas armadas de un estado se establece: 
Artículo 4. 1. Los grupos armados distintos de las fuerzas armadas de un Estado no deben en ninguna circunstancia reclutar o utilizar en hostilidades a menores de 18 años. 2. Los Estados Partes adoptarán todas las medidas posibles para impedir ese reclutamiento y utilización, con inclusión de la adopción de las medidas legales necesarias para prohibir y tipificar esas prácticas. 3. La aplicación del presente artículo no afectará la situación jurídica de ninguna de las partes en un conflicto armado.

De esta manera, se descarta la posibilidad de que fuerzas no estatales recluten o utilicen en hostilidades a menores de 18 años y se obliga a los Estados Parte a adoptar las medidas necesarias para evitar tales prácticas.

Otro de los instrumentos internacionales de mayor relieve es el Estatuto de Roma que ve su creación concretarse cuando la Asamblea General de la ONU decidió llamar a la Conferencia Diplomática de Plenipotenciarios de las Naciones Unidas sobre el establecimiento de una Corte Penal Internacional para finalizar y adoptar una Convención sobre el establecimiento de una Corte Penal Internacional. La Conferencia de Roma se llevó a cabo entre el 15 de junio y 17 de julio de 1998 en la ciudad de Roma (Italia) y contó con la participación de 160 países en las negociaciones. Luego de concluir las cinco semanas de negociaciones, 120 naciones votaron a favor de la adopción del Estatuto de Roma de la Corte Penal Internacional, siete naciones votaron en contra, entre ellas Estados Unidos, Israel, China, Irak y Catar, y 21 estados se abstuvieron ${ }^{30}$.

Este Estatuto declara la competencia de la Corte Penal Internacional para los llamados Crímenes de Guerra, que conforme al mismo estatuto en el artículo 8, 2. a) consisten en infracciones graves de los Convenios de Ginebra de 12 de agosto de 1949. Este Estatuto trae una lista de actos contra personas o bienes protegidos por las disposiciones del Convenio de Ginebra pertinente y además consagra otras violaciones graves de las leyes y usos aplicables en los conflictos armados internacionales dentro del marco establecido de derecho internacional. El literal b) xxvi) hace referencia a reclutar o alistar a niños menores de 15 años en las fuerzas armadas nacionales o utilizarlos para participar activamente en las hostilidades ${ }^{31}$.

En 1997, se aprobaron los Principios de Ciudad del Cabo, resultado de un simposio organizado del 27 al 30 de abril por UNICEF y la organización no gubernamental Grupo de Trabajo sobre la Convención sobre los Derechos del Niño, para formular estrategias destinadas a evitar el reclutamiento de niños, desmovilizar a los niños soldados y ayudarles a reintegrarse en la sociedad. El conocimiento generado a raíz de esta experiencia ha llevado a adoptar un enfoque más local y exhaustivo, se ha producido cada vez mayor concienciación sobre las dimensiones múltiples de la utilización de niños por fuerzas armadas o grupos armados y las complejidades que se derivan de abordar el problema y sus causas profundas. Todo ello devino en la promulgación de dos importantes documentos: Los Compromisos de París, para proteger a los niños reclutados o utilizados ilícitamente por fuerzas armadas o grupos armados, y Los Principios de París, un documento complementario que contiene los principios y directrices sobre los niños asociados con fuerzas armadas o grupos armados, que ofrecen una orientación más precisa para todos aquellos que se encargan de la aplicación de programas. En una reunión ministerial celebrada en París en febrero de 2007 se obtuvo un amplio apoyo político de los Estados a los Compromisos de París y a los Principios de París ${ }^{32}$.

En el apartado 1.6, Los principios reconocen que, en situaciones de conflicto armado, los Estados y grupos armados son los principales responsables de la protección de los civiles que están bajo su control, y que si no pueden o no quieren cumplir con todas sus responsabilidades humanitarias están obligados a habilitar responsables imparciales para que realicen una acción humanitaria. En el apartado 2.1, por "niño o niña asociado con una fuerza armada o un grupo armado" se entiende cualquier persona menor de 18 años de edad que haya sido reclutada o utilizada por una fuerza armada o un grupo armado en cualquier tipo de función, aunque no limitados, los niños y niñas utilizados como combatientes, cocineros, porteadores, mensajeros, espías o con fines sexuales. No se refieren solamente a un niño o niña que estén participando o hayan participado directamente en las hostilidades. También el apartado 2.4 señala: Por "reclutamiento" se entiende la conscripción o alistamiento de niños y niñas en cualquier tipo de fuerza armada o grupo armado. El apartado 2.5 indica: Por “reclutamiento o utilización ilícitos" se entiende el reclutamiento o la utilización de 
niños y niñas cuya edad sea menor de la estipulada en los tratados internacionales aplicables a la fuerza armada o el grupo armado en cuestión, o bajo las leyes nacionales aplicables. Y finalmente el apartado 2.9 indica que: Por "reinserción de niños y niñas" se entiende el proceso por medio del cual se inicia una transición de los niños y niñas a la sociedad civil y la adopción de funciones e identidades válidas como civiles que son aceptadas por sus familias y comunidades en el contexto de una reconciliación local y nacional. Una reinserción sostenible se logra cuando se hayan garantizado las condiciones políticas, jurídicas, económicas y sociales necesarias para que los niños y niñas mantengan sus vidas, sus medios de sustento y su dignidad. Este proceso tiene por objetivo que los niños y niñas puedan disfrutar sus derechos, entre ellos a la educación oficial y no oficial, a la unidad familiar, a un sustento digno y a la seguridad contra cualquier tipo de peligro ${ }^{33}$.

\section{Los niños y su tratamiento como sujetos de especial protección reforzada en el derecho interno colombiano en el marco de la implementación del Acuerdo de Paz con las FARC-EP}

\section{El reclutamiento forzado de los niños y su tratamiento en las normas internas}

El reconocimiento de los niños como sujetos de derecho y su especial protección tuvieron una importante manifestación en Colombia a través de la expedición del Decreto 2737 de 1989, denominado Código del Menor $^{34}$, cuyo paradigma para el trato de los derechos de los niños era el de la protección. Entre las situaciones irregulares que contenía dicha normativa no estaba el que los niños hubiesen sido reclutados de manera forzosa o voluntaria por los grupos ilegales. Aunque el enfoque de protección al menor era identificable en las anteriores legislación y Constitución [1886], su alcance fue hondamente cuestionado a la luz de la Convención sobre los Derechos del Niño de 1989, frente a la cual la Constitución de 1886 presentaba fallas ${ }^{35}$ . En este sentido, el Comité para los Derechos del Niño de las Naciones Unidas manifestó en varias ocasiones al Estado colombiano su preocupación por la falta de adecuación de la normatividad nacional a los principios y disposiciones de la Convención en cuanto a la garantía y el respeto a la aplicación de los Derechos Humanos del menor dentro del orden de Derecho Público Interno, de cara al sistema constitucional ${ }^{36}$.

El proceso de reforma en Colombia fue muy dispendioso y duró muchos años. En efecto, varias iniciativas fracasaron en el Congreso de la República. Pero, finalmente, una iniciativa conjunta de entidades del gobierno, el Ministerio Público, el Sistema de las Naciones Unidas y organizaciones no gubernamentales nacionales e internacionales reunidos en la Alianza por la Niñez y un grupo de legisladores establecieron un espacio de trabajo permanente que duró más de tres años y cuyo fruto fue el actual Código de la Infancia y la Adolescencia (CIA), expedido mediante la Ley 1098 de $2006^{37}$.

El reconocimiento de los niños como víctimas del reclutamiento forzado en Colombia solo se hace visible con la expedición de la Ley 418 de 1997, que estableció el delito de reclutamiento ilícito. Rezaba el artículo 14: "quien reclute a menores de edad para integrar grupos insurgentes o grupos de autodefensa, o los induzca a integrarlos, o los admita en ellos, o quienes con tal fin les proporcione entrenamiento militar, será sancionado con prisión de tres a cinco años”. Este artículo fue modificado por el artículo 5 de la Ley 1421 de 2010 que, además de las sanciones penales para quienes sean condenados por reclutamiento ilícito de menores de edad, señaló que estos no podrán ser acreedores de los beneficios jurídicos consagrados en la misma Ley.

La Ley 548 de 1999 prorrogó la vigencia de la Ley 418 de 1997, como un esfuerzo encaminado a proteger a niños, niñas y adolescentes de la participación o reclutamiento por parte de las diversas instancias que conforman la fuerza pública colombiana. Esta ley prohibió, entre otras, el servicio militar y el reclutamiento de personas menores de 18 años a las fuerzas militares. Lo anterior, sin importar por ejemplo que la voluntad del adolescente y la de sus padres se mostrara a favor de la incorporación de la persona menor de 18 años a la 
fuerza pública o se apelara al argumento según el cual los menores no eran destinados a zonas con operaciones de guerra o confrontaciones armadas, tal como lo preveía la Ley 418 de $1997^{38}$.

Colombia ratificó la Convención de los Derechos del Niño mediante la Ley 12 de 1991, pero al momento de la ratificación el Estado colombiano hizo una reserva sobre el contenido de dicho instrumento, en virtud de la cual debía entenderse que la edad mínima para que una persona pueda participar en las hostilidades del conflicto armado es de 18 años. En ese sentido, sin perjuicio de la modificación que posteriormente fue introducida por el Protocolo Facultativo de la Convención sobre los Derechos del Niño relativo a la participación de los niños en conflictos armados ${ }^{39}$, la protección que el artículo 38 de la Convención sobre los Derechos del Niño dispensa en favor de los niños ante el riesgo de su participación en un conflicto armado, debe entenderse en favor de todos los menores de 18 años en Colombia desde $1991^{40}$.

El Gobierno colombiano aprobó y ratificó los dos Protocolos Optativos de la Convención: la Ley 765 de 2002, de 31 de julio, por medio de la cual se aprueba el Protocolo Facultativo de la Convención sobre los Derechos del Niño relativo a la venta de niños, la prostitución infantil y la utilización de los niños en la pornografía, adoptado en Nueva York el veinticinco (25) de mayo de dos mil (2000); y la Ley 833 de 2003, de 10 de julio, por medio de la cual se aprueba el Protocolo Facultativo de la Convención sobre los Derechos del Niño relativo a la participación de niños en los conflictos armados, aprobado en Nueva York el veinticinco (25) de mayo de dos mil (2000) ${ }^{41}$.

Tras esta disposición, el Ejército Nacional desmovilizó de sus filas a finales de 1999 a más de ochocientos menores de dieciocho años. Así mismo, a inicios de 2000, la Policía Nacional prohibió la incorporación de menores de dieciocho años en sus propias filas ${ }^{42}$.

En el año 2000, mediante la Ley 599, se aprobó un nuevo Código Penal. En el título II del Libro II, relativo a los delitos contra personas y bienes protegidos por el derecho internacional humanitario, el artículo 162 establece: "El que, con ocasión y en desarrollo de conflicto armado, reclute menores de dieciocho (18) años o los obligue a participar directa o indirectamente en las hostilidades o en acciones armadas, incurrirá en prisión de seis (6) a diez (10) años y multa de seiscientos (600) a mil (1.000) salarios mínimos legales mensuales vigentes (SMLMV). Esta pena fue aumentada con la Ley 890 de 2004, al pasar de ocho (8) a quince (15) años de prisión y la multa pasó de ochocientos (800) a mil quinientos (1.500) SMLMV.

Colombia aprobó el Estatuto de Roma de la Corte Penal Internacional mediante la Ley 742 de 2002 y, por tanto, el carácter de crimen de guerra del delito de reclutamiento; específicamente, el Estatuto señala el delito de reclutar o alistar a niños menores de 15 años en las fuerzas armadas nacionales o utilizarlos para participar activamente en las hostilidades.

Sin embargo, al momento de ratificar el Estatuto de Roma, el Congreso lo hizo con la salvedad prevista en el artículo 124 de un período de siete años contados a partir de la fecha en que el Estatuto entró en vigor, o sea, el 1 de noviembre de 2002, y no se aceptó la competencia de la Corte Penal Internacional sobre la categoría de crímenes de guerra, entre los cuales está el de reclutamiento. Por tanto, solo a partir del 1 de noviembre de 2009 la Corte Penal Internacional tuvo plena jurisdicción para investigar y sancionar el reclutamiento de menores de 15 años en Colombia ${ }^{43}$.

En el informe Una guerra sin edad, el CENTRO NACIONAL DE MEMORIA HISTÓRICA trae a colación que:

En 2005 el Secretario General de las Naciones Unidas identificó seis graves violaciones que pueden ser cometidas en contra de niños y niñas en tiempos de guerra o en medio de un conflicto armado y, frente a las cuales los Estados tienen el deber de hacer monitoreo y reportar las acciones realizadas encaminadas a la protección de las personas menores de edad en riesgo o que han sido víctimas. Reclutamiento y uso de niños ha sido incluido junto con abduction en el grupo de las seis graves violaciones dentro de las cuales también hace parte la muerte y mutilación de niños; violencia sexual en contra de niños; ataque en contra de escuelas y hospitales y denegación del acceso de los niños a la ayuda humanitaria (Office of the Special Representative of the Secretary-General for Children and Armed Conflict, 2013, página 9). El Manual de monitoreo y mecanismos de reporte 
de graves violaciones en situaciones de conflicto armado (2010, página 11) de la ONU (Organización de las Naciones Unidas) plantea la definición abduction de la siguiente manera:

La sustracción, detención, captura, aprehensión, toma o desaparición forzada ilegal de un niño, ya sea temporal o permanente para el propósito de cualquier explotación del niño — esto incluye, pero no se limita - al reclutamiento dentro de fuerzas o grupos armados, participación en hostilidades, explotación o abuso sexual, trabajo forzado, toma de rehenes, o adoctrinamiento. Si un niño es reclutado por la fuerza por una fuerza o grupo armado esto es considerado como dos violaciones separadas, ser secuestrado y reclutado 44 .

\section{Estado de cosas inconstitucional por desplazamiento forzado y reclutamiento de menores de 18 años}

La situación provocada por el conflicto armado interno había producido un fenómeno de desplazamiento forzado de altas magnitudes. En vista de ello, la Sentencia T-025-04 de la Corte Constitucional ${ }^{45}$ declara que respecto de la población desplazada por la violencia existía un "estado de cosas inconstitucional como una falla estructural y/o una política pública del Estado", pues era tal la magnitud de la violación de los derechos humanos de dicha población, que más que una demanda contra una o varias entidades del Estado, se trataba de un problema estructural, derivado de graves falencias en la actuación de un conjunto amplio de instituciones que forman parte de lo que la ley ha llamado el Sistema Nacional de Atención Integral a la Población Desplazada (SNAIPD) ${ }^{46}$. Además, la Corte precisó que cuando el Estado omite sin justificación constitucionalmente aceptable tomar medidas frente a la marginación que sufren algunos miembros de la sociedad, y se verifica que la inhibición viola un derecho constitucional fundamental, la función del juez será "no la de remplazar a los órganos del poder público incursos en la abstención, sino la ordenar el cumplimiento de los deberes del Estado" ${ }^{47}$.

En el marco del seguimiento a ese Estado de Cosas por el desplazamiento forzado, en consideración a las investigaciones generadas por la Defensoría del Pueblo, la Corte Constitucional en el Auto A251-08 se pronuncia sobre la "protección de los derechos fundamentales de los niños, niñas y adolescentes desplazados por el conflicto armado", allí sostiene que los niños, niñas y adolescentes desplazados por el conflicto armado son sujetos de protección constitucional imperativa y prioritaria, en virtud de los mandatos de la Carta Política y de las obligaciones internacionales del Estado colombiano en materia de Derechos Humanos y Derecho Internacional Humanitario ${ }^{48}$.

El riesgo de reclutamiento forzoso de menores de edad por los grupos armados ilegales que participan en el conflicto armado colombiano es reconocido en dicho auto como una ocurrencia extendida y reiterada en todo el territorio nacional. La Corte Constitucional admite que es un hecho comprobado que el reclutamiento forzado de menores de edad — niños, niñas y adolescentes - es una práctica criminal en la que incurren en forma extensiva, sistemática y habitual los grupos armados ilegales que toman parte en el conflicto armado en Colombia, tanto guerrillas como paramilitares. Así mismo, la Corte señala el reclutamiento forzado de menores como causa directa de desplazamiento forzado a través de cuatro mecanismos causales distintos:

i. el desplazamiento forzado de familias y comunidades enteras, ante el riesgo de que sus niños, niñas y adolescentes sean vinculados al conflicto armado, bien sea por amenazas recibidas directamente contra la vida de los menores o de sus familias, por el peligro generalizado existente en una región determinada, o porque uno o más miembros de la familia o la comunidad ya han sido reclutados y se quiere evitar que otros también lo sean;

ii. el desplazamiento forzado de las familias de los menores de edad efectivamente reclutados, puesto que el reclutamiento de un niño, niña o adolescente implica una presión y persecución para sus parientes, por parte de los actores armados enfrentados; 
iii. el desplazamiento forzado de las familias de los menores de edad que han sido reclutados pero han desertado, para proteger sus vidas; $y$

iv. el desplazamiento forzado únicamente de los niños, niñas o adolescentes en riesgo, que son enviados o se trasladan a otros lugares para preservarlos o preservarse del peligro de reclutamiento.

La Corte sostiene que los niños, niñas y adolescentes desplazados por el conflicto armado son sujetos de protección constitucional imperativa y prioritaria, en virtud de los mandatos de la Carta Política y de las obligaciones internacionales del Estado colombiano en materia de Derechos Humanos y Derecho Internacional Humanitario ${ }^{49}$.

Así, la Constitución Política consagra:

Artículo 44. Son derechos fundamentales de los niños: la vida, la integridad física, la salud y la seguridad social, la alimentación equilibrada, su nombre y nacionalidad, tener una familia y no ser separados de ella, el cuidado y amor, la educación y la cultura, la recreación y la libre expresión de su opinión. Serán protegidos contra toda forma de abandono, violencia física o moral, secuestro, venta, abuso sexual, explotación laboral o económica y trabajos riesgosos. Gozarán también de los demás derechos consagrados en la Constitución, en las leyes y en los tratados internacionales ratificados por Colombia. La familia, la sociedad y el Estado tienen la obligación de asistir y proteger al niño para garantizar su desarrollo armónico e integral y el ejercicio pleno de sus derechos. Cualquier persona puede exigir de la autoridad competente su cumplimiento y la sanción de los infractores. Los derechos de los niños prevalecen sobre los derechos de los demás 50 .

Con relación a la edad, en el Auto A251-08 la Corte defiende que debe tenerse en cuenta que los adolescentes - quienes son de por sí titulares de los derechos de los niños por ser menores de 18 añostambién son beneficiarios de un mandato constitucional de protección especial, que se consagra en el artículo 45 superior:

Artículo 45. El adolescente tiene derecho a la protección y a la formación integral. El Estado y la sociedad garantizan la participación activa de los jóvenes en los organismos públicos y privados que tengan a cargo la protección, educación y progreso de la juventud.

La Corte Constitucional además reconoce que el Estado de Cosas derivado del desplazamiento forzado infringe las obligaciones del Estado emanadas de los instrumentos internacionales, tales como la Declaración Universal de Derechos Humanos (art. 25-2); la Declaración Americana de los Derechos y Deberes del Hombre que dispone que todo niño tenga derecho a "protección, cuidados y ayuda especiales" (art. VII); el Pacto Internacional de Derechos Civiles y Políticos dispone que: "todo niño tiene derecho, sin discriminación alguna por motivo de raza, color, sexo, idioma, religión, origen nacional o social, posición económica o nacimiento, a las medidas de protección que su condición de menor requiere, tanto por parte de su familia como de la sociedad y del Estado" (art. 24-1). La Convención Americana sobre Derechos Humanos establece que: "todo niño tiene derecho a las medidas de protección que su condición de menor requiere por parte de su familia, de la sociedad y del Estado" (art. 19). El Protocolo adicional a la Convención Americana sobre Derechos Humanos, en materia de derechos económicos, sociales y culturales, Protocolo de San Salvador, dispone que: "todo niño sea cual fuere su filiación tiene derecho a las medidas de protección que su condición de menor requiere por parte de su familia, de la sociedad y del Estado" (art. 16). Y concretamente la Convención sobre los Derechos del Niño, que en términos generales establece que: "los Estados Partes respetarán los derechos enunciados en la presente Convención y asegurarán su aplicación a cada niño sujeto a su jurisdicción, sin distinción alguna (...)" (art. 2-1); que "los Estados Partes se comprometen a asegurar al niño la protección y el cuidado que sean necesarios para su bienestar, teniendo en cuenta los derechos y deberes de sus padres, tutores u otras personas responsables de él ante la ley y, con ese fin, tomarán todas las medidas legislativas y administrativas adecuadas" (art. 3-2), y que "los Estados Partes adoptarán todas las medidas administrativas, legislativas y de otra índole para dar efectividad a los derechos reconocidos en la presente Convención (art. 4)" ${ }^{51}$. 
Asimismo, hace énfasis en que el Derecho Internacional Humanitario es claramente aplicable al conflicto armado interno colombiano y que obliga al Estado a proporcionar a los niños, niñas y adolescentes una especial protección frente a las graves violaciones de sus derechos fundamentales derivadas de la confrontación, particularmente las que conlleva el desplazamiento forzado, conforme lo señala la Corte Constitucional de Colombia en la Sentencia C-291-07 ${ }^{52}$.

Así lo menciona el Protocolo II adicional a los Convenios de Ginebra de 1977, que incluye entre las "garantías fundamentales" de la que son titulares las personas no combatientes, el que "se proporcionarán a los niños los cuidados y la ayuda que necesiten" (art. 4-3). La Convención sobre los Derechos del Niño también obliga al Estado colombiano a proteger a los menores de edad afectados por el conflicto armado interno: el artículo 38-1 establece que: "los Estados Partes se comprometen a respetar y velar por que se respeten las normas del Derecho Internacional Humanitario que les sean aplicables en los conflictos armados y que sean pertinentes para el niño", y el artículo 38-2 dispone que "de conformidad con las obligaciones dimanadas del Derecho Internacional Humanitario de proteger a la población civil durante los conflictos armados, los Estados Partes adoptarán todas las medidas posibles para asegurar la protección y el cuidado de los niños afectados por un conflicto armado" 53 .

Resulta importante señalar que, por medio del mecanismo de la Resolución 1612, Colombia está siendo monitoreada frente a las violaciones contra los niños, niñas y adolescentes enunciadas, a través del Consejo de Seguridad de las Naciones Unidas ${ }^{54}$.

En 2006 se aprobó la Ley 1098 de Infancia y Adolescencia, cuyo paradigma era el garantismo constitucional. Esta ley introdujo diferentes mecanismos para la atención y prevención del reclutamiento forzado. El artículo 3 estableció que todas las personas menores de dieciocho años son sujetos titulares de derechos; el artículo 7 consagró el principio de protección integral de las personas menores de dieciocho años, específicamente señaló que se entiende por protección integral de los niños, niñas y adolescentes el reconocimiento como sujetos de derechos, la garantía y cumplimiento de los mismos, la prevención de su amenaza o vulneración y la seguridad de su restablecimiento inmediato en desarrollo del principio del interés superior. Y adicionó que la protección integral se materializa en el conjunto de políticas, planes, programas y acciones que se ejecuten en los ámbitos nacional, departamental, distrital y municipal con la correspondiente asignación de recursos financieros, físicos y humanos.

A su vez, el artículo 8 estableció que los derechos de los niños, niñas y adolescentes son universales, prevalentes e interdependientes. La prevalencia se señaló en el artículo 9 en el que se dice que, en todo acto, decisión o medida administrativa, judicial o de cualquier naturaleza que deba adoptarse en relación con los niños, las niñas y los adolescentes, prevalecerán los derechos de estos, en especial si existe conflicto entre sus derechos fundamentales con los de cualquier otra persona. Y se añade que, en caso de conflicto entre dos o más disposiciones legales, administrativas o disciplinarias, se aplicará la norma más favorable al interés superior del niño, niña o adolescente.

El artículo 10 determinó la corresponsabilidad entendida como la concurrencia de actores y acciones conducentes a garantizar el ejercicio de los derechos de los niños, las niñas y los adolescentes. Se hace énfasis en que la familia, la sociedad y el Estado son corresponsables en su atención, cuidado y protección. La norma señaló que, tanto la corresponsabilidad, como la concurrencia aplican en la relación que se establece entre todos los sectores e instituciones del Estado. Y se hace la salvedad de que, pese a todo ello, las instituciones públicas o privadas obligadas a la prestación de servicios sociales no podrán invocar el principio de la corresponsabilidad para negar la atención que demande la satisfacción de derechos fundamentales de niños, niñas y adolescentes.

Cabe destacar que el artículo 20 señaló explícitamente que los niños, las niñas y los adolescentes serán protegidos contra el reclutamiento y la utilización de los niños por parte de los grupos armados organizados al margen de la ley (numeral 7$)^{55}$. 


\section{Los niños soldados de las FARC-EP}

\section{Reclutamiento forzado}

Este fenómeno es uno de los acontecimientos más tristes que pueda registrar la humanidad y ha sido una constante en todos los países con conflictos armados, como Ruanda, Congo, Sierra Leona... Para vergüenza, Colombia no es una excepción. En el documento técnico Lineamientos del Consejo Nacional de Reincorporación (CNR) para el Programa Integral Especial de Restitución de los Derechos de los Niños, Niñas y Adolescentes que salgan de las FARC-EP, del programa Camino Diferencial de Vida, se reconoce que el conflicto colombiano no ha sido ajeno a esta situación. "El ingreso de menores de edad a los Grupos Armados Organizados al Margen de la Ley (GAOML) es ciertamente un fenómeno multicausal. La Defensoría del Pueblo en un Informe del año 2006 menciona factores de índole social, familiar, económico, cultural y afectivo [sic] que inciden como factores de vulnerabilidad para el reclutamiento de niños, niñas y adolescentes. Los contextos de privación económica, la falta de acceso a servicios de educación, salud, bienestar y recreación, así como la carencia de redes afectivas y de protección, entre otras condiciones de vulnerabilidad, influyen de manera determinante en el ingreso de esta población a los grupos. También se encuentra el hecho de que algún o algunos de sus familiares sean miembros del GAOML" ${ }^{56}$.

De muchos casos que son buenos ejemplos que muestran la magnitud del problema se da cuenta en la cobertura de noticias de los medios de comunicación de todo el país:

El desmovilizado ex jefe paramilitar Freddy Rendón, alias El Alemán, admitió que entre sus filas había 358 niños reclutados de 1999 a 2005. Según dijo, al momento de su desmovilización reunió a 149 menores y los envió para sus casas. Solo tres fueron entregados al Instituto Colombiano de Bienestar Familiar. No se sabe qué fue peor, si reclutarlos y utilizarlos para la guerra, o regresarlos a sus casas sin opciones diferentes para sus vidas. Quedaron desprotegidos y sin los beneficios de la reinserción tales como estudio, ayuda sicológica y aporte económico. La mayoría de estos niños son de Dabeiba y Necoclí, en Urabá, y el Atrato Medio Chocoano 57

En enero, en una vereda de Leticia, un comando de las Farc citó a padres de familia y líderes de la comunidad para notificarles que debían presentarse al día siguiente con sus hijos mayores de 15 años para prestar servicio obligatorio en el \#Ejército del Pueblo\#. Indignado, el cura de la zona reunió a los padres en la iglesia y les ordenó no entregar a sus hijos y esconderlos. Entonces les llovieron amenazas y el sacerdote y algunas familias no tuvieron más opción que dejar el pueblo. Casos similares se han repetido en Guainía, Vichada, Meta, Caquetá, Putumayo y hasta en Bogotá, porque la guerrilla está empeñada en el reclutamiento de menores. Muchos padres, antes que entregar a sus hijos, prefieren huir y abandonarlo todo. Otros no han tenido más opción que dejarlos en poder de las Farc 58 .

De raspachines a guerrilleros: así reclutan menores en el Catatumbo. La amenaza de reclutamiento forzado de menores de edad por parte de las FARC y el ELN es tan grave, que ha obligado a que los niños y jóvenes abandonen su trabajo como raspachines en los extensos sembradíos de uso ilícito. Hace no menos de 20 días conocí el caso de una jovencita de tan solo 14 años de edad que se la llevó la guerrilla de las Farc. Eso fue en el sector de Caño Trece, del corregimiento La Gabarra, municipio de Tibú, en Norte de Santander. Días antes, otras dos jóvenes del mismo sector se fueron para la insurgencia. La gente afirma haberlas visto un par de veces tratando de convencer a muchachos de su edad para que se fueran con ellas. La revelación la hizo Laura, habitante de Tibú, municipio ubicado en la región del Catatumbo, una vasta zona geográfica compuesta por montañas, bosques y selvas tropicales, ubicada en Norte de Santander, en límites con la República Bolivariana de Venezuela. Su testimonio fue reforzado por Carlos, un líder comunitario del municipio, quien afirmó que desde hace meses se vienen registrando casos de reclutamiento forzado de menores de edad por parte de grupos guerrilleros en otras zonas del departamento. "Sí, eso está ocurriendo. He conocido casos en veredas como Luis Vero y Filo Gringo", revela la fuente. La crudeza del fenómeno fue puesta en evidencia el pasado 14 de abril, cuando el Ejército Nacional reportó la muerte en combate de siete guerrilleros del Ejército de Liberación Nacional (ELN), en hechos ocurridos en la vereda El Suspiro, corregimiento de La Gabarra. Tras verificar las identidades de los abatidos, se comprobó que cuatro de ellos eran los jóvenes Emilio, de 17 años de edad; Camila, también de 17 años; Julián, de 14 años y Pedro, de tan solo 12 años de vida 59.

Todo ello refleja que, durante la existencia del conflicto armado, el reclutamiento forzado fue una práctica habitual en las FARC-EP. Las cifras no han sido muy claras a lo largo de la historia; sin embargo, en el informe 
Una guerra sin edad, se da cuenta de un fuerte incremento del fenómeno entre 1997 y 2005: "Con 9.199 casos, equivalentes al 54,5 por ciento de la muestra total de la base del OMC [Observatorio de Memoria y Conflicto], entre 1997 y 2005 se da un hito en el reclutamiento de niños, niñas y adolescentes al registrarse el mayor número de casos, lo que confirmó la tendencia al incremento de inicios de los noventa para llegar a un pico máximo en 2003 con 7.136 niños, niñas y adolescentes reclutados por los diferentes actores armados" ${ }^{60}$.

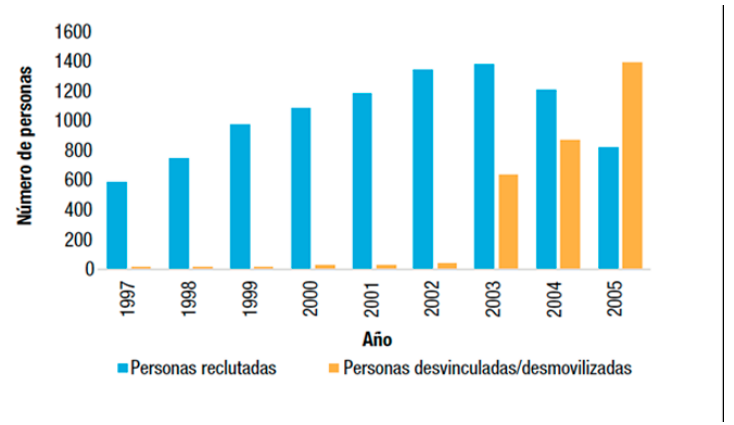

FIGURA 1

Niños, niñas y adolescentes reclutados y desvinculados/desmovilizados, 1997-2005

Fuente: Colombia, CENTRO NACIONAL DE MEMORIA HISTÓRICA, CNMH, Una guerra

sin edad. Informe nacional de reclutamiento y utilización de niños, niñas y adolescentes en el conflicto armado colombiano, 122 (Centro Nacional de Memoria Histórica, CNMH Bogotá, 2017). Disponible en: http://www.centrodememoriahistorica.gov.co/descargas/informes2018/una_guerra-sin-edad.pdf

En el informe se sostiene que los datos obtenidos de la base del Observatorio de Memoria y Conflicto, $\mathrm{OMC}$, refrendan que en el proceso de reclutamiento las variaciones regionales son inocultables y tienen estrecha relación con las bases consolidadas por los actores armados en los territorios en donde lograron una fuerte regulación de la vida cotidiana y social. Los picos desagregados por actor muestran que tanto guerrillas como paramilitares apelaron a sus bases sociales a la hora de reclutar para llevar a cabo sus procesos expansivos o las disputas territoriales ${ }^{61}$. Además, se demuestra con cifras que no fue un tema rural sino también urbano. La figura 2 muestra las personas reclutadas por regiones.

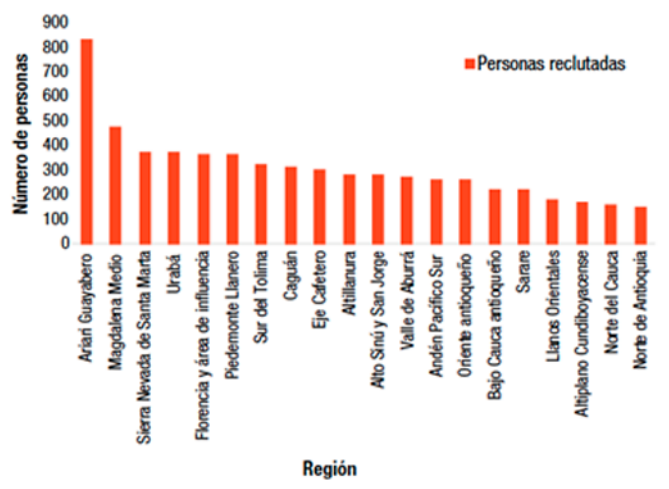

FIGURA 2

Top 20 de regiones de reclutamiento, 1997-2005 Fuente: Colombia, CENTRO NACIONAL DE MEMORIA HISTÓRICA, CNMH, Una guerra sin edad. Informe nacional de reclutamiento y utilización de niños, niñas y adolescentes en el conflicto armado colombiano, 123 (Centro Nacional de Memoria Histórica, CNMH Bogotá, 2017). Disponible en: http://www.centrodememoriahistorica.gov.co/descargas/informes2018/una_guerra-sin-edad.pdf

Finalmente, el informe es contundente al afirmar que de acuerdo con la base de datos del OMC este da cuenta de 16.879 registros de reclutamiento y utilización de niños, niñas y adolescentes por parte de grupos armados en el marco del conflicto colombiano que, más allá de la cifra de por sí significativa a la luz de la vulneración de derechos, lo que está detrás son las trayectorias de vida de niños, niñas y adolescentes cuyo devenir ha estado signado por la guerra ${ }^{62}$. 


\section{Negociaciones de La Habana y Acuerdo de Paz}

En el marco de las conversaciones de La Habana, las delegaciones del Gobierno Nacional y las FARC-EP llegaron a un acuerdo sobre los niños soldados y su salida de los campamentos. Los puntos centrales de tal negociación fueron dos. Respecto de los menores de 15 años se acordó que abandonarían los campamentos, para lo cual se programaría su entrega inmediata y, respecto de los mayores de 15 años, se llegó a un compromiso con la elaboración de una hoja de ruta para la salida de todos los demás menores de edad, así como la creación de un programa integral especial para su atención.

Este acuerdo fue conocido mediante Comunicado Conjunto No. 70, del 15 de mayo de 2016. Se presentaron demoras en la ejecución de las entregas y el país quedó en una alarmante espera para que se diera lugar la salida de niños menores de 15 años de los campamentos.

Los Diálogos de Paz adelantados entre el Gobierno Nacional y las FARC-EP dieron finalmente vida al Acuerdo final para la terminación del conflicto y la construcción de una paz estable y duradera, en el que se definió la protección integral de los derechos de los menores de edad vinculados al conflicto armado, como un propósito compartido, resultado de lo cual, acordaron medidas especiales para su protección, disponiendo en el Numeral 3.2.2.5 la Reincorporación para los menores de edad que han salido de los campamentos de las FARC-EP, en los siguientes términos:

Los menores de edad que hayan salido de los campamentos de las FARC-EP desde el inicio de las conversaciones de paz, así como los que salgan hasta la finalización del proceso de la dejación de armas, serán objeto de medidas de especial atención y protección que se discutirán en el Consejo Nacional de Reincorporación en el marco de la Comisión de Seguimiento, Impulso y Verificación de la Implementación del Acuerdo Final (CSIVI) y que incluirán los principios orientadores que serán de aplicación a los menores de edad y los lineamientos para el diseño del Programa Especial conforme a lo establecido en el Comunicado Conjunto No. 70 de fecha 15 de mayo de 2016 para garantizar la restitución de sus derechos con enfoque diferencial, priorizándose su acceso a la salud y a la educación. A estos menores de edad se les reconocerán todos los derechos, beneficios y prestaciones establecidos para las víctimas del conflicto, así como los derivados de su proceso de reincorporación en los términos contemplados en el Acuerdo Final y se priorizará su reagrupación familiar cuando ello sea posible, así como su ubicación definitiva en sus comunidades de origen o en otras de similares características, siempre teniendo en cuenta el interés superior del niño. El seguimiento a estos programas se efectuará por el Consejo Nacional de Reincorporación en articulación con las entidades del Estado competentes y con el apoyo de organizaciones sociales o especializadas encargadas de hacer la veeduría en los términos del Comunicado Conjunto No. 70. La elaboración del Programa Especial de Reincorporación para menores deberá realizarse por parte del Consejo Nacional de Reincorporación, con base en la propuesta presentada por parte de la mesa técnica creada mediante Comunicado Conjunto No. 70. Una vez aprobado el Programa, el Gobierno Nacional tramitará los ajustes normativos que sean necesarios para garantizar su implementación, siempre teniendo en cuenta el interés superior del niño y el Derecho Internacional Humanitario.

El Programa deberá garantizar la reincorporación integral del menor y su acompañamiento psicosocial, con la veeduría de las organizaciones sociales o especializadas en los términos del Comunicado Conjunto No. 70, así como también su ubicación en lugares transitorios de acogida en municipios cercanos a las Zonas Veredales Transitorias de Normalización, garantizando el derecho a la información de todos los participantes, en especial a los niños, niñas y adolescentes ${ }^{63}$.

El Acto Legislativo No. 01 de 2016, por el cual se establecen instrumentos jurídicos para facilitar y asegurar la implementación y el desarrollo normativo del Acuerdo Final para la terminación del conflicto y la construcción de una paz estable y duradera, confirió al Presidente de la República una habilitación legislativa extraordinaria y excepcional para expedir decretos con fuerza material de ley, de naturaleza instrumental, pues tienen por objeto facilitar y asegurar la implementación y desarrollo normativo del Acuerdo de Paz. Así, mediante Decreto 2027 de 2016, se creó el Consejo Nacional de Reincorporación, como instancia que define actividades, cronograma y adelanta el seguimiento del proceso de reincorporación de los integrantes de las FARC-EP a la vida legal y estableció entre sus funciones discutir las medidas especiales de atención y protección de los niños, niñas y adolescentes que hayan salido o salgan de los campamentos, así como elaborar los lineamientos del Programa Integral Especial y realizar seguimiento al programa. 
El punto 5 de los 6 del Acuerdo Final busca la creación de un Sistema Integral de Verdad, Justicia, Reparación y no Repetición para garantizar los derechos de las víctimas del conflicto. El sistema está conformado por una Comisión de Esclarecimiento de la Verdad, la Unidad para la Búsqueda de Personas Desaparecidas, las medidas de reparación integral para la construcción de paz y la Jurisdicción Especial para la Paz -JEP_ que es el componente de justicia del sistema ${ }^{64}$.

El Acto Legislativo 1 del 4 de abril de 2017 creó el Sistema Integral de Verdad, Justicia, Reparación y no Repetición, determinó la estructura de la JEP, las funciones de los órganos que la componen y precisó otros aspectos sobre su competencia y naturaleza.

\section{La condición de víctimas antes y después del Acuerdo de Paz. Los que siendo menores de 18 años fueron reclutados son víctimas del conflicto armado}

En virtud de la Ley 418 de 1997, previo y al margen del proceso de paz entre el Gobierno Nacional y las FARC-EP, el Instituto Colombiano de Bienestar Familiar (ICBF) es la entidad encargada de diseñar y ejecutar un programa especial de protección para la asistencia a los niños, niñas y adolescentes víctimas del conflicto armado, provenientes de cualquier grupo armado al margen de la ley, para promover la corresponsabilidad estatal, social y familiar según las competencias y garantizar el restablecimiento de derechos ${ }^{65}$.

Bajo este precepto, desde 1999, el ICBF implementó con recursos públicos suficientes el Programa de Atención Especializada para el restablecimiento de derechos a niños y adolescentes víctimas de reclutamiento ilícito que se han desvinculado de grupos armados organizados al margen de la ley, el cual tiene como objetivo garantizar la protección integral a estos niños a través de medidas de restablecimiento de derechos y contribución a la reparación integral ${ }^{66}$.

Como marco regulador de la defensa de los derechos de las víctimas del conflicto armado en Colombia se erige la Ley 1448 de 2011 o Ley de Víctimas, por la cual se dictan medidas de atención, asistencia y reparación integral a las víctimas del conflicto armado interno. Esta norma señala en su artículo 1:

Objeto. Establecer un conjunto de medidas judiciales, administrativas, sociales y económicas, individuales y colectivas, en beneficio de las víctimas de las violaciones contempladas en el artículo 3 de la presente ley, dentro de un marco de justicia transicional, que posibiliten hacer efectivo el goce de sus derechos a la verdad, la justicia y la reparación con garantía de no repetición, de modo que se reconozca su condición de víctimas y se dignifique a través de la materialización de sus derechos constitucionales 67

Esta ley constituye una referencia de protección a los niños reclutados víctimas del conflicto armado en la medida en que contempla un apartado exclusivo para la Protección integral a los niños, niñas y adolescentes víctimas (TÍTULO VII). En su desarrollo, el artículo 181 señala, que para los efectos de esta ley se entenderá por niño, niña y adolescente toda persona menor de 18 años. Se puntualiza en que los niños, niñas y adolescentes víctimas de las violaciones contempladas en el artículo 3 de esta ley, gozarán además de todos los derechos civiles, políticos, sociales, económicos y culturales, con el carácter de preferente, entre otros, a los derechos de:

1. A la verdad, la justicia y la reparación integral.

2. $\mathrm{Al}$ restablecimiento de sus derechos prevalentes.

3. A la protección contra toda forma de violencia, perjuicio o abuso físico o mental, malos tratos o explotación, incluidos el reclutamiento ilícito, el desplazamiento forzado, las minas antipersona y las municiones sin explotar y todo tipo de violencia sexual.

En la sentencia C-253A-12, la Corte Constitucional señaló que la previsión conforme a la cual se reconoce a los menores de edad que hagan parte de organizaciones armadas organizadas al margen de la ley la condición 
de víctima, se ajusta a los estándares internacionales sobre la materia y constituye un desarrollo de las exigencias del ordenamiento superior en relación con el deber de protección de los menores de edad. Por otra parte, la Corte estima que la condición para que resulta aplicable este marco de protección es precisamente la de ser menores de edad ${ }^{68}$.

Para armonizar el programa de atención especializada a la luz de la Ley 1448 de 2011, el Instituto Colombiano de Bienestar Familiar, mediante Resolución 1525 del 23 de febrero de 2016, aprobó el Lineamiento técnico de las modalidades del programa de atención especializada para el restablecimiento de derechos a niños, niñas y adolescentes victimas de reclutamiento ilícito, que se han desvinculado de grupos armados organizados al margen de la ley y contribución al proceso de reparación integral, el cual se enmarca en el enfoque de protección integral, incluyendo a su vez las acciones orientadas a restablecer la vigencia efectiva de los derechos de las víctimas, brindarles condiciones para llevar una vida digna, propender por su incorporación a la vida social, económica y política, así como proporcionar información, orientación y acompañamiento jurídico y psicosocial con miras a facilitar el acceso a los derechos a la verdad, la justicia y la reparación ${ }^{69}$.

Con el objeto de atender la desvinculación de niños, niñas y adolescentes, que se consagra en el acuerdo de paz e implementar el punto 3.2.2.5 de dicho acuerdo referente a la reincorporación de los menores de edad que han salido de los campamentos de las FARC-EP, en cumplimiento de tales compromisos, el gobierno nacional diseñó el Camino diferencial de vida: programa de atención y consolidación de los proyectos de vida de los menores de 18 años que salen de las FARC-EP, el cual se basa en el interés superior del niño y sus derechos prevalentes, para garantizar el restablecimiento de sus derechos, su reparación integral y su reincorporación, sin perder de vista que todo ello ocurre como resultado de un Acuerdo de Paz y en el marco del tránsito a la legalidad de las FARC-EP. Esta situación abre nuevos retos a las instituciones del Estado frente a los ajustes de carácter normativo, institucional, operativo y política pública con el fin de dar respuesta a la necesidad planteada de manera integral, a cargo de la Alta Consejería Presidencial para los Derechos Humanos. Este programa contempla cuatro procesos a saber: i) salida y traslado de los menores de edad; ii) restablecimiento de derechos; iii) reparación integral y iv) reincorporación e inclusión social ${ }^{70}$.

En la sentencia C-541-17, se refrenda que:

Bajo este diseño y en el marco de sus competencias legales, el Instituto Colombiano de Bienestar Familiar ha realizado las siguientes acciones:

a. Verificación de las condiciones de los lugares transitorios de acogida (locación para la ubicación de los menores de edad señalada en el Programa Camino Diferencial de Vida) y de estándares técnicos, administrativos, legales y financieros de los operadores propuestos por la OIM y UNICEF.

Para este efecto, el ICBF expidió la Resolución 350 del 27 de enero de 2017, modificada mediante Resolución 1940 de 2017, \#por medio de la cual se establecen los requisitos para la autorización de la prestación del servicio de protección integral en contingencia para niños, niñas y adolescentes desvinculados de grupos armados organizados al margen de la ley\#. En el marco de estas resoluciones, se han otorgado nueve (9) autorizaciones para la prestación del servicio de protección por parte de organizaciones contratadas por los citados cooperantes internacionales.

b. Asistencia técnica a nueve (9) Defensorías de Familia y a sus equipos técnicos interdisciplinarios e igual número de equipos psicosociales de los operadores, sobre la desvinculación de menores de edad en el marco del proceso de Paz, el punto 3.2.2.5 del Acuerdo Final, los lineamientos del Programa Camino Diferencial de Vida aprobados por el Consejo Nacional de Reincorporación, los roles de los diferentes actores intervinientes y muy especialmente, sobre el Proceso Administrativo de Restablecimiento de Derechos de acuerdo con lo establecido en la Ley 1098 de 2006, Ley 1448 de 2011, normatividad relacionada y lineamientos técnicos administrativos del ICBF...

... De acuerdo con el objeto misional del ICBF, las disposiciones legales vigentes y en el marco del Acuerdo Final para la Terminación del Conflicto y la Construcción de una Paz Estable y Duradera, las Defensorías de Familia y sus equipos interdisciplinarios han dado inicio a procesos administrativos de restablecimiento de derechos a favor de 75 adolescentes entregados por las FARC-EP en lo corrido del 2017, quienes fueron ubicados en los lugares transitorios de acogida, tal y como se muestra a continuación, según el departamento en el que fueron entregados: 


\begin{tabular}{|l|c|}
\hline Departamento de desvinculación & Total \\
\hline Antioquia & 18 \\
\hline Arauca & 5 \\
\hline Caquetá & 13 \\
\hline Guaviare & 10 \\
\hline Meta & 13 \\
\hline Norte de Santander & 6 \\
\hline Puerto Asís & 10 \\
\hline Total niños, niñas y adolescentes & $\mathbf{7 5}$ \\
\hline
\end{tabular}

d. Asignación de interlocutores permanentes para apoyar la implementación del Programa Camino Diferencial de Vida y participación en espacios de coordinación (p.e. sesiones del Consejo Nacional de Reincorporación, reuniones con la Consejería Presidencial para los Derechos Humanos y/o la Oficina del Alto Comisionado para la Paz) ${ }^{71}$.

La discusión en torno a quienes se aplican estos programas ha generado la expedición de dos decretos de ley modificatorios del artículo 190 de la Ley 1448 de 2011, que regula lo concerniente al derecho a la reparación integral de todos los niños, niñas y adolescentes víctimas del reclutamiento. El artículo 190 establece que los niños, niñas y adolescentes víctimas del delito de reclutamiento ilícito podrán reclamar la reparación del daño, de acuerdo con la prescripción del delito consagrada en el artículo 83 del Código Penal. Reza además que la restitución de los derechos de los niños, niñas y adolescentes estará a cargo del Instituto Colombiano de Bienestar Familiar y que una vez los niños, niñas y adolescentes cumplan la mayoría de edad, podrán ingresar al proceso de reintegración social y económica que lidera la Alta Consejería para la Reintegración Social y Económica de Personas y Grupos Alzados en Armas, siempre que cuenten con la certificación de desvinculación de un grupo armado organizado al margen de la ley, expedida por el Comité Operativo para la Dejación de las Armas.

En la sentencia C-541-17, la Corte Constitucional declaró exequible el Decreto Ley 891 de 2017, del 28 de mayo de 2017, por el cual se adiciona el parágrafo transitorio estableciendo que cuando en el curso de la desvinculación de menores de edad que se dé en desarrollo del Acuerdo Final para la Terminación del Conflicto y la Construcción de una Paz Estable y Duradera, el Instituto Colombiano de Bienestar Familiar compruebe su mayoría de edad con fundamento en la verificación realizada por la Registraduría Nacional del Estado Civil u otro agente del Sistema Nacional de Bienestar Familiar, estas personas podrán permanecer en los lugares transitorios de acogida hasta cuando se vinculen a la oferta institucional dispuesta para ellas, de conformidad con el programa Camino Diferencial de Vida ${ }^{72}$. La Corte lo hace en el entendido de que "los programas de reintegración social y económica en favor de menores víctimas de reclutamiento ilícito, incluidos quienes alcanzaron la mayoría de edad, forman parte del derecho a la reparación que comporta también la restitución, que deben ser asegurados por el Estado".

Y finalmente por el Decreto 671 de 2017 se modifica la Ley 1448 de 2011, en lo relacionado con la certificación de la desvinculación de menores en casos de Acuerdos de Paz.

\section{La discusión de la edad en el tratamiento de los niños soldados}

Después de este recuento de la evolución del tema del reclutamiento de niños en los conflictos armados y en su tratamiento en el ámbito internacional e interno, revisaremos dos interrogantes que se plantean respecto de la edad en cuanto al juzgamiento de este crimen en el marco de la Jurisdicción Especial para la Paz. Ello es un factor determinante frente al derecho de los niños víctimas de este flagelo a la verdad, la justicia, la reparación integral, las garantías de no repetición y al restablecimiento de sus derechos prevalentes.

El primero es cuál es la edad que se tendrá en cuenta para la aplicación de las normas de Derecho Internacional Humanitario y del Derecho Internacional de los Derechos Humanos, lo que nos conduce a establecer cómo responderán las FARC-EP frente a este crimen contra los niños víctimas del reclutamiento forzado. El segundo de ellos es de qué manera va a repercutir la edad de reclutamiento en el tratamiento de 
los casos de Amnistía e Indulto, es decir, cómo van a responder los guerrilleros de las FARC-EP que tienen condición de víctima y victimario. Intentaremos abordar las respuestas actuales a tales interrogantes.

\section{Amnistía e indulto. La Corte Constitucional y la solución ambigua}

Mediante Ley 1820 de 2016 se dictan disposiciones sobre amnistía, indulto y tratamientos penales especiales a los integrantes de las Farc-EP que suscribieron el Acuerdo Final, además de a los agentes de la Fuerza Pública que incurrieron en conductas típicas, incluso constitutivas de violaciones de derechos humanos, en el marco, o en relación directa o indirecta, con el conflicto armado interno.

La Corte Constitucional en la sentencia C-007-18 analiza la constitucionalidad del artículo 23 de la Ley 1820 de 2016, denominada regla de exclusión de amnistias, indultos y renuncia a la persecución penal. Procedemos a realizar un estudio de los apartados más relevantes que definen el asunto de la edad.

La Corte Constitucional reconoce el clamor de los intervinientes en demandar un máximo de protección para niños y adolescentes, esto es, para todas aquellas personas que, siendo menores de 18 años, han participado en el conflicto. Pero se afinca en sostener que tal postura en defensa del interés superior de niños, niñas y adolescentes no resuelve el problema jurídico que enfrenta la Corte en esta oportunidad. Admite que el reclutamiento de personas menores de 18 años está prohibido en Colombia. Pero insiste en que el problema radica en verificar si, al definir el alcance de la regla de exclusión de amnistías es válido utilizar una remisión al Estatuto de Roma que como vimos mantiene un estándar más bajo de protección que el Protocolo Facultativo relativo a la participación de los niños en los conflictos armados. Y admite que sea afirmativa o negativa, ello no implica que el Estado pueda obviar la protección especial de los niños y adolescentes víctimas del conflicto.

Interpreta que la alusión del parágrafo del artículo 23 literal a) al Estatuto de Roma por parte del Legislador dista de ser caprichosa, y sostiene que la idea central acerca del núcleo de lo que no puede ser objeto de un beneficio de amnistía -o indulto o renuncia a la persecución penal-general, absoluta, incondicional o autoconferida, está definida a manera de mínimos intangibles en el derecho internacional, o sea, en este caso el del Estatuto de Roma; pero que por fuera de esos mínimos hay un amplio margen de configuración legislativa destinado a definir la ponderación adecuada entre los beneficios, que se dirigen a la paz y la reconciliación, y los derechos de las víctimas, percibidos en un enfoque holístico e integral, con lo cual califica la remisión de razonable.

También analiza si es proporcionada teniendo en cuenta la existencia de otras normas en el derecho penal internacional (convencional o consuetudinario) que definan, como crimen de guerra el reclutamiento antes de los 18 años. Para ello hace una revisión de las normas penales internas en los términos en que se hacen en el presente documento, concluyendo que en Colombia, solo a través de una ley de 1997, posteriormente reforzada en 1999, y finalmente vertida en un tipo penal, el ordenamiento interno estableció la prohibición definitiva, tanto del reclutamiento (participación forzada), como del alistamiento (participación voluntaria), de niños en el conflicto.

Llama la atención que en lo referente a la Convención de los Derechos del Niño hace alusión genérica a los países que la han ratificado, sosteniendo que "solo hasta la aprobación del Protocolo Facultativo a la Convención de los Derechos del Niño, relativo a la participación de niños en conflictos armados, se observa la decisión de los Estados de ampliar la prohibición hasta la edad citada”. Lastimosamente, pasa por alto la reserva que Colombia hace a la Convención de los Derechos del Niño en virtud de la cual debía entenderse que la edad mínima para que una persona pueda participar en las hostilidades del conflicto armado es de 18 años, conforme se destaca en su propia sentencia C-069-16 ${ }^{73}$.

Pasa entonces la Corte a verificar si este crimen ha sido definido como crimen de guerra en el Derecho Penal Internacional, en términos tales que hagan inadmisible acoger la fórmula del Estatuto de Roma, o que exijan fortalecer el estándar de lo no amnistiable. Para ello hace un recorrido en los términos del presente 
documento respecto a los cuatro Convenios de Ginebra, de 12 de agosto de 1949, y de los Protocolos adicionales a los mencionados Convenios fijando la fecha en 1977 como aquella en la que emergió la necesidad de prohibir específicamente el reclutamiento de menores. Destaca que el Protocolo Adicional II aplicable a confrontaciones armadas no internacionales dispuso que "los niños menores de quince años no serán reclutados en las fuerzas o grupos armados y no se permitirá que participen en las hostilidades".

Para concluir, desoladamente, que "si bien es claro que existe un crimen de guerra asociado a las conductas que llevan a la participación de niños, niñas y adolescentes menores de 15 años en el conflicto armado, no es igualmente claro que esta categoría (la de crimen de guerra) se extienda, de forma unívoca en el derecho internacional relevante a las personas entre los 15 y 18 años. Lo que se percibe en el ámbito internacional es un fortalecimiento progresivo de la prohibición y una intención ya definida de elevar el estándar del crimen hasta los 18 años".

Para sentar su postura se amarró al Amicus curiae de la Unicef ante el Tribunal Especial para Sierra Leona, TESL, las providencias del Tribunal citado en el fallo y el número de ratificaciones y adhesiones al Protocolo facultativo de la Convención sobre los Derechos del Niño relativo a la participación de niños en los conflictos armados (PFCDNPCA), y concluyó que puede afirmarse que, por lo menos, al momento de entrada en vigor del referido instrumento para Colombia (25 de junio de 2005), la prohibición del reclutamiento de menores de 18 años, como un crimen internacional, forma parte del derecho consuetudinario y su comisión acarrea responsabilidad penal individual.

Resumió las razones para esta posición en estas consideraciones: (i) al 2001, cerca del 80\% de los Estados con edad de reclutamiento obligatorio la establecían en 18 años o más, y la misma edad era establecida por 74 de los 126 Estados con reclutamiento voluntario; (ii) tanto el TESL como Unicef concuerdan en que el proceso de desarrollo relativo al reclutamiento de niños soldados menores de 18 años culminó con la codificación de la cuestión en el PFCDNPCA; (iii) Colombia fue el Estado número 98 en obligarse por el mencionado instrumento; y (iv) la adopción de esta posición no implica la definición de un crimen, sino únicamente la precisión acerca del estándar de aplicación de beneficios dentro de la Ley 1820 de 2016.

De esta forma, la Corte resalta que se satisface lo pactado entre las partes al momento de suscribir el Acuerdo Final, pero, además, se respetan al máximo los derechos de las víctimas y las obligaciones estatales en lo que tiene qué ver con el alcance de las excepciones válidas al deber de investigar, juzgar y sancionar las violaciones a los derechos humanos.

Entonces, la Corporación concluye que la expresión "reclutamiento de menores conforme a lo establecido en el Estatuto de Roma”, contenida en distintas disposiciones de la Ley 1820 de 2016 (artículos 23, 30, 46, 47, 52 y 57) debe entenderse así: "el reclutamiento de menores de 15 años en el caso de conductas ocurridas hasta el 25 de junio de 2005, y el reclutamiento de menores de 18 años en el caso de conductas ocurridas con posterioridad a esa fecha”.

Esta conclusión sostiene que no es solo aplicable a la regla de exclusión de amnistías, indultos y renuncia a la persecución penal, sino también a otros artículos de la Ley; concretamente, a todos aquellos que incorporan la misma remisión al Estatuto de Roma, con fines distintos a la exclusión de responsabilidad penal; por ejemplo, a efectos de establecer la procedencia de beneficios de libertad o de privación de esta en lugares especiales.

Con la venia, no compartimos la opción elegida por el Alto Tribunal, pues en sus términos había otras hipótesis hermenéuticas frente a la escogida por la Sala, como la de elegir por fecha de consolidación del crimen la entrada en vigor del PFCDNPCA, o la que para nosotros es de mayor recibo en términos de interpretación de la norma cuestionada, aquellas en que se produjo la penalización en el derecho interno, es decir, desde la vigencia de la Ley 418 de 1997. Ello en concordancia con que, al momento de la ratificación de la Convención de los Derechos del Niño, Colombia asumió una postura totalmente garantista, al prohibir el reclutamiento de menores de $\mathbf{1 8}$ años en las fuerzas armadas y dar ejemplo en el panorama internacional, que solo logró ampliar el margen de edad en el año 2002. Esta situación ocurrida en el Derecho Interno, de pleno conocimiento por todos los actores armados, ha debido prevalecer por encima de la observación en 
torno a que la Corte está obligada a determinar cuándo, sin lugar a duda se encuentra cristalizada la norma de derecho consuetudinario, con el fin de evitar una lesión al debido proceso y a la prohibición de irretroactividad penal, incluso cuando este se flexibiliza como ocurre en el derecho internacional. Tal postura viola, en nuestra opinión, tanto las obligaciones internacionales derivadas de la ratificación de la Convención de los Derechos del Niño, como nuestro derecho interno que sanciona uno de los delitos más atroces que ha sufrido nuestro país, un crimen contra la humanidad. La misma Corte Constitucional sentaba precedente al respecto en la mencionada sentencia C-069-16 y ello debió ser así en atención del prevalente interés superior de los niños, niñas y adolescentes victimas del conflicto armado .

\section{Otras opciones desde la protección especial reforzada como víctimas en el DIH y el DIDH}

Continuando con el análisis de la sentencia C-007-18, es de anotar que el déficit de protección derivado de esta subregla que reconoce el Alto Tribunal, intenta cubrirlo al abordar tres aspectos: (i) la condición de víctimas de los niños, niñas y adolescentes dentro del conflicto, hasta los 18 años, y su consecuencia jurídica sobre el numeral 10 del artículo 28 de la Ley 1820 de 2016; (ii) la necesidad de establecer una regla de investigación sobre la probable ocurrencia de conductas no amnistiables derivadas del reclutamiento y sus consecuencias jurídicas en el marco de la Ley de amnistía; y, finalmente, (iii) el carácter continuo de las conductas a las que se refiere este eje temático.

Todo ello tomando como base los Compromisos y los Principios de París 2007. Los Principios le sirven de fundamento para justificar que el derecho sancionador definido en los términos anteriormente señalados, es un medio de protección de este grupo poblacional, pero no es el único. En consecuencia, define un conjunto de estándares que deberán ser considerados por los órganos del Sistema de Verdad, Justicia, Reparación y No Repetición.

Básicamente, se relaciona con el trato como víctimas de los menores de 18 años que sufrieron este flagelo, que participaron o fueron utilizados por los grupos armados dentro del conflicto; con la aplicación de políticas de reinserción, rehabilitación, cuidado y protección, acordes con sus intereses y respetuosas del principio de igualdad y el mandato de no discriminación ${ }^{74}$. Y de la especial afectación sufrida por las niñas, y ordena adoptar medidas diferenciales para su reintegración, considerando, entre otros aspectos, el estigma social que pueden enfrentar en sus comunidades al momento del retorno, la necesidad de generación de ingresos y la atención de sus hijos, nacidos en medio de la guerra ${ }^{75}$.

Esta solución puede resultar en la práctica incoherente o al menos contradictoria con el estándar de edad adoptado por el Alto Tribunal en la sentencia de análisis. Sin embargo, se adentra en ello al señalar la magnitud del crimen.

Destaca que quienes fueron reclutados u obligados a participar en el conflicto armado sin cumplir los 18 años de edad son víctimas de una seria violación a un "catálogo de derechos fundamentales" ${ }^{76}$.

La Corte señala que "las víctimas menores de edad tienen derecho a conocer la verdad, acceder a la justicia y obtener una reparación adecuada por este hecho. Pero, además, por su condición de vulnerabilidad al momento del reclutamiento, los órganos de la Jurisdicción Especial para la Paz deberán asumir, como una obligación reforzada, la garantía de los derechos de las personas menores de 18 años que se vieron obligadas a participar en el conflicto, en tanto víctimas particularmente vulnerables del conflicto mismo, y como garantía de no repetición de una conducta que debe ser erradicada definitivamente de cualquier conflicto armado. [Deber de protección reforzada a los derechos de los menores de 18 años, como víctimas especialmente vulnerables de reclutamiento forzado]" 77 .

Ordena: "un monitoreo especial y reforzado al cumplimiento del deber de contribución de los perpetradores de estas conductas a los derechos de las víctimas, aun de aquellos que accedan a los beneficios de mayor entidad de la Ley 1820 de 2016, que son las amnistías, los indultos y la renuncia a la persecución 
penal. [Deber reforzado de contribución de los perpetradores, como condición de acceso y preservación de beneficios]" 78 .

Enfatiza en que "Las personas que fueron reclutadas antes de los 18 años entraron al conflicto armado antes de alcanzar la madurez; sufrieron la ruptura traumática de sus vínculos familiares; y enfrentaron el drama de asumir desde una etapa temprana de sus vidas el conflicto armado, de forma directa o indirecta. Más allá de la discusión sobre las amnistías, indultos y TPED [Tratamientos Penales Especiales Diferenciados], lo expresado refleja una doble situación de vulnerabilidad, que pudo hacerlos blanco de otros delitos y atentados a su dignidad, tales como (i) servidumbre o trabajos forzados; (ii) sometimiento a tratos y penas crueles, inhumanas y degradantes; y (iii) diversas formas de agresión sexual, por solo mencionar algunos de los más graves. Así, por ejemplo, Human Rights Watch, el Centro Nacional de Memoria Histórica y Codhes [Consultoría para los Derechos Humanos y el Desplazamiento], en el contexto colombiano, han señalado que el reclutamiento ha estado ligado a otras conductas no amnistiables (v.gr. violencia sexual)" ${ }^{79}$.

Por ello, ordena que "los órganos de la JEP, tratándose del reclutamiento de menores de 18 años y mayores de 15, reclutados cuando el estándar no estaba consolidado, tienen el deber de cerciorarse de que no dejen de perseguirse esas otras conductas, por lo que deben remitir las diligencias a la Sala u órgano competente para iniciar, de oficio, investigaciones serias en las que se determine si, a raíz del reclutamiento de personas menores de 18 años se produjeron, en concurso con este delito, otras conductas no amnistiables o que no sean objeto de cualquier otro tratamiento penal especial. [Deber de investigación oficiosa de conductas no amnistiables]" ${ }^{80}$.

\section{Una deuda pendiente con la infancia perdida}

El segundo de los interrogantes que nos planteamos es de qué manera va a repercutir la edad de reclutamiento en el tratamiento de los casos de amnistía e indulto, es decir, cómo van a responder los guerrilleros de las FARC-EP que tienen condición de víctimas y victimarios del conflicto armado; víctimas por aparecer en los expedientes de reclutamiento forzado; victimarios por aparecer también en la comisión de masacres, secuestros, extorsiones y vejaciones cometidas mientras estaban en las filas. Pero con la particularidad de contar con mayoría de edad durante las negociaciones y hasta el momento de dejación de las armas.

Este crimen generalizado y el proceso que ha sufrido el Acuerdo de Paz con las FARC-EP, dan cuenta de que, durante todo el conflicto armado de más de 60 años, la práctica aberrante de reclutamiento forzado de niños fue una constante, lo cual nos pone frente al panorama de que los mandos medios y soldados pueden reunir estas características: ser víctimas y victimarios de este conflicto. Nunca podrán establecerse una verdad, una justicia, una reparación y una garantía de no repetición, si no tenemos en cuenta que Colombia tiene una deuda con la infancia perdida de miles de personas, niños y niñas, que luego fueron hombres y mujeres que no pudieron elegir no participar en el conflicto armado, porque de una u otra manera se vieron forzados a ser actores del mismo o incluso nacieron dentro de las filas de los grupos al margen de la ley. Las respuestas a esta inquietud no están claras en este momento histórico.

Pero, con base en los datos del informe Una guerra sin edad, sí puede considerarse probado que más de 16.000 personas identificadas con nombre y apellido han sufrido este flagelo ${ }^{81}$. Que en los datos suministrados por el Instituto Colombiano de Bienestar Familiar sobre los cupos para las modalidades de atención de niños, niñas y adolescentes víctimas del conflicto armado, se plantean y presupuestan alrededor de 2.000 cupos por año (vigencia de 2017) ${ }^{82}$ y que toda esta información no concuerda con el insignificante número de niños y niñas (75 a 2017) registrados en el programa Camino Diferencial de Vida y cuyo número de entrega fue estimado en 100 personas. Todo ello nos deja frente a la repetición de la lamentable experiencia en el proceso de las Autodefensas, pues de acuerdo al artículo 10 de la Ley 975 de 2005 uno de los requisitos para que los paramilitares accedieran a la desmovilización colectiva era la entrega de niños y adolescentes 
vinculados a estos grupos, poniéndolos a disposición del ICBF. No obstante, el proceso adelantado hizo caso omiso a esta exigencia, evadió la entrega de los niños y adolescentes vinculados a sus filas, e invisibilizó el tema en las declaraciones y audiencias dadas por los jefes paramilitares ante la justicia.

¿Será que los interrogantes que se plantearon son aplicables en un país cuya experiencia en la protección de víctimas data ya de más de 17 años? Hoy podemos preguntarnos, como lo hacíamos entonces: "Si no hay certezas sobre el número de NNA que fueron vinculados a estos grupos y si además resulta altamente factible que la cantidad superara con creces la cifra consolidada en materia de atención estatal ¿cuál ha sido entonces el paradero de los niños y niñas que conformaban estos frentes?” 83 ¿Se quedarán al margen de las políticas de implementación del Acuerdo de Paz, en términos de verdad, justicia, reparación, garantías de no repetición y restablecimiento pleno de sus derechos, la mayoría de los niños y niñas víctimas del reclutamiento forzado por parte de la guerrilla de las FARC-EP, que después de más de cuatro años de negociaciones en La Habana, logró firmar un Acuerdo de Paz con el Gobierno Nacional?

\section{Conclusiones}

1. Se hace una aproximación al concepto de niños soldados en Colombia y se afirma que se trata de todas aquellas personas menores de 18 años que forman o han formado parte de cualquier tipo de fuerza armada se trate del Ejército regular o de grupos armados al margen de la ley, hayan o no portado armas y con indiferencia de las labores que realicen o a las actividades a las que sean sometidos dentro de estos grupos.

2. El drama que ha vivido la infancia colombiana por el reclutamiento forzado se evidencia en los miles de niños y niñas que hacen parte de los programas de desvinculación del conflicto armado. Los niños, niñas y adolescentes que se han desmovilizado vienen con mayor frecuencia de las FARC-EP.

3. En 1989 se produjo un hito en el panorama de la defensa internacional de los derechos de los niños y niñas. Los derechos de la infancia están plenamente estipulados en la Convención sobre los Derechos del Niño. Elaborada durante 10 años con las aportaciones de representantes de diversas sociedades, culturas y religiones, la Convención fue aprobada como tratado internacional de derechos humanos el 20 de noviembre de 1989. En lo relativo a la participación y utilización de los niños en los conflictos armados, la Convención de 1989 hace referencia específica en los artículos 38 y 39. Reviste especial importancia que Colombia introdujo una reserva en su ratificación al hacer alusión al contenido de dicho instrumento, en virtud de la cual debía entenderse que la edad mínima para que una persona pueda participar en las hostilidades del conflicto armado es de 18 años. En ese sentido, sin perjuicio de la modificación que posteriormente fue introducida por el Protocolo Facultativo de la Convención sobre los Derechos del Niño relativo a la participación de los niños en conflictos armados, la protección que el artículo 38 de la Convención sobre los Derechos del Niño dispensa en favor de los niños ante el riesgo de su participación en un conflicto armado, debe entenderse en favor de todos los menores de 18 años en Colombia desde 1991.

4. El reconocimiento de los niños como víctimas del reclutamiento forzado en Colombia solo se hace visible tras la expedición de la Ley 418 de 1997 que estableció el delito de reclutamiento ilícito. Rezaba el artículo 14: "quien reclute a menores de edad para integrar grupos insurgentes o grupos de autodefensa, o los induzca a integrarlos, o los admita en ellos, o quienes con tal fin les proporcione entrenamiento militar, será sancionado con prisión de tres a cinco años". Este artículo fue modificado por el artículo 5 de la Ley 1421 de 2010, que además de las sanciones penales para quienes sean condenados por reclutamiento ilícito de menores de edad, señaló que estos no podrán ser acreedores de los beneficios jurídicos consagrados en la misma ley. Esta ley fue expedida y puesta 
en vigencia durante la existencia del conflicto armado colombiano, por tanto, era conocida y debía ser respetada por todos los actores del conflicto. Las normas del Código Penal son aplicables en la Jurisdicción Especial para la Paz.

5. La Corte Constitucional admite que es un hecho comprobado que el reclutamiento forzado de menores de edad - niños, niñas y adolescentes - es una práctica criminal en la que incurren en forma extensiva, sistemática y habitual los grupos armados ilegales que toman parte en el conflicto armado en Colombia, tanto guerrillas como paramilitares. Así mismo, la Corte señaló el reclutamiento forzado de menores como causa directa de desplazamiento forzado que generó la declaratoria del estado de cosas inconstitucional.

6. En 2006 se aprobó la Ley 1098 de Infancia y Adolescencia, cuyo paradigma era el garantismo constitucional. Esta ley introdujo diferentes mecanismos para la atención y prevención del reclutamiento forzado. El artículo 8 establece que los derechos de niños y adolescentes son universales, prevalentes e interdependientes. La prevalencia se señala en el artículo 9 en el que se dice que en todo acto, decisión o medida administrativa, judicial o de cualquier naturaleza que deba adoptarse en relación con los niños, las niñas y los adolescentes, prevalecerán los derechos de estos, en especial si existe conflicto entre sus derechos fundamentales con los de cualquier otra persona. Y se añade que, en caso de conflicto entre dos o más disposiciones legales, administrativas o disciplinarias, se aplicará la norma más favorable al interés superior del niño, niña o adolescente.

7. El informe Una guerra sin edad da cuenta de 16.879 registros de reclutamiento y utilización de niños, niñas y adolescentes por parte de grupos armados en el marco del conflicto colombiano y se afirma que, más allá de la cifra de por sí significativa a la luz de la vulneración de derechos, lo que está detrás son las trayectorias de vida de niños, niñas y adolescentes cuyo devenir ha estado signado por la guerra. Los Diálogos de Paz adelantados entre el Gobierno Nacional y las FARC-EP dieron finalmente vida al Acuerdo final para la terminación del conflicto y la construcción de una paz estable y duradera, que definió la protección integral de los derechos de los menores de edad vinculados al conflicto armado, como un propósito compartido, resultado de lo cual, acordaron medidas especiales para su protección y dispusieron en el numeral 3.2.2.5 la reincorporación para los menores de edad que han salido de los campamentos de las FARC-EP.

8. Con el objeto de atender la desvinculación de niños, niñas y adolescentes que se consagra en el Acuerdo de paz e implementar el punto 3.2.2.5 de ese acuerdo referente a la reincorporación de los menores de edad que han salido de los campamentos de las FARC-EP, el Gobierno Nacional, en cumplimiento de tales compromisos, diseñó el Camino diferencial de vida: programa de atención y consolidación de los proyectos de vida de los menores de 18 años que salen de las FARC-EP. Las Defensorías de Familia y sus equipos interdisciplinarios han iniciado procesos administrativos de restablecimiento de derechos a favor de 75 adolescentes entregados por las FARC-EP en lo corrido de 2017, que fueron ubicados en los lugares transitorios de acogida.

9. La pregunta sobre cuál es la edad que se tendrá en cuenta para la aplicación de las normas de Derecho Internacional Humanitario y de Derecho Internacional de los Derechos Humanos, nos conduce a establecer cómo responderán las FARC-EP frente a este crimen contra los niños y niñas víctimas del reclutamiento forzado. Se responde que el Gobierno colombiano expidió la Ley 833 de 2003 (julio 10) por medio de la cual se aprueba el Protocolo Facultativo de la Convención sobre los Derechos del Niño relativo a la participación de niños en los conflictos armados, aprobado en Nueva York el veinticinco (25) de mayo de dos mil (2000), que rige en Colombia desde el 25 de junio de 2005; esta fecha fue tenida en cuenta por la Corte colombiana para la participación de niños, niñas y adolescentes en el conflicto, como crimen de guerra y el estándar de edad del sujeto pasivo, como persona menor de 15 años. 
10. Al momento de ratificar el Estatuto de Roma, el Congreso de Colombia lo hizo con la salvedad prevista en el artículo 124 de un período de siete años contados a partir de la fecha en que el Estatuto entró en vigor, o sea, el 1 de noviembre de 2002, y no se aceptó la competencia de la Corte Penal Internacional sobre la categoría de crímenes de guerra, entre los cuales está el de reclutamiento. Por tanto, solo a partir del 1 de noviembre de 2009 la Corte Penal Internacional tuvo plena jurisdicción para investigar y sancionar el reclutamiento de menores de quince años en Colombia. Sin embargo, este Estatuto fija la edad de prohibición del reclutamiento forzado en 15 años.

11. La Corte Constitucional concluye entonces que la expresión "reclutamiento de menores conforme a lo establecido en el Estatuto de Roma", contenida en distintas disposiciones de la Ley 1820 de 2016 (artículos 23, 30, 46, 47, 52 y 57) debe entenderse así: "el reclutamiento de menores de 15 años en el caso de conductas ocurridas hasta el 25 de junio de 2005, y el reclutamiento de menores de 18 años en el caso de conductas ocurridas con posterioridad a esa fecha”.

12. No compartimos la opción elegida por el Alto Tribunal, pues en sus términos había otras hipótesis hermenéuticas frente a la escogida por la Sala, como la de elegir por fecha de consolidación del crimen la entrada en vigor del PFCDNPCA, o la que para nosotros es de mayor recibo en términos de interpretación de la norma cuestionada, aquellas en que se produjo la penalización en el derecho interno, es decir, desde la vigencia de la Ley 418 de 1997. Ello en concordancia con que, al momento de la ratificación de la Convención de los Derechos del Niño, Colombia asumió una postura totalmente garantista, al prohibir el reclutamiento de menores de 18 años en las fuerzas armadas y dio ejemplo en el panorama internacional.

13. En cuanto al interrogante sobre de qué manera va a repercutir la edad de reclutamiento en el tratamiento de los casos de amnistía e indulto, es decir, cómo van a responder los guerrilleros de las FARC-EP que tienen condición de víctima y victimario, se puede decir que en un conflicto armado que duró más de 60 años, la práctica aberrante de reclutamiento forzado de niños y niñas fue una constante. Esto nos pone frente al panorama de que los mandos medios y soldados pueden reunir estas características: ser víctimas y victimarios de este conflicto. Colombia tiene una deuda con la infancia perdida de miles de personas, niños y niñas, que luego fueron hombres y mujeres que no pudieron elegir no participar en el conflicto armado, porque de una u otra manera se vieron forzados a ser actores del mismo o incluso nacieron dentro de las filas de los grupos al margen de la ley. Las respuestas a esta inquietud no están claras en este momento histórico.

14. Con base en los datos del informe Una guerra sin edad, puede considerarse probado que más de 16.000 personas identificadas con nombre y apellido han sufrido este flagelo. Que en los datos suministrados por el Instituto Colombiano de Bienestar Familiar sobre los cupos para las modalidades de atención de niños, niñas y adolescentes víctimas del conflicto armado, se plantean y presupuestan alrededor de 2.000 cupos por año (vigencia de 2017) y que toda esta información no concuerda con el insignificante número de niños y niñas (75 a 2017) registrados en el programa Camino Diferencial de Vida y cuyo número de entrega fue estimado en 100 personas. Todo ello nos deja frente a la repetición de la lamentable experiencia en el proceso de las Autodefensas, pues de acuerdo al artículo 10 de la Ley 975 de 2005 uno de los requisitos para que los paramilitares accedieran a la desmovilización colectiva era la entrega de niños y adolescentes vinculados a estos grupos, al ponerlos a disposición del ICBF. No obstante, el proceso adelantado hizo caso omiso a esta exigencia, evadió la entrega de los niños y adolescentes vinculados a sus filas, e invisibilizó el problema.

15. Son amnistiables los delitos de reclutamiento forzado perpetrados contra los menores de edad, sean niñas o niños, que tuviesen menos de 18 años y más de 15 a junio de 2005. 


\section{Bibliografía}

\section{Libros}

ARELLANO-VELASCO, MARCELA, Uso y participación de niños en conflictos armados (Editorial de la Universidad de Granada, Granada, 2008). Disponible en: https://hera.ugr.es/tesisugr/17707134.pdf

GÓMEZ-ISA, FELIPE, La participación de los niños en los conflictos armados (Colección Cuadernos Deusto Derechos Humanos 10, Publicaciones Universidad de Deusto, Bilbao, 2000). Disponible en: http://www.deusto-publica ciones.es/deusto/pdfs/cuadernosdcho/cuadernosdcho10.pdf

ORAÁ-ORAÁ, JAIME \& GÓMEZ-ISA, FELIPE, La Declaración Universal de los Derechos Humanos. Un breve comentario en su 50 aniversario (Publicaciones Universidad de Deusto, Bilbao, 1997). Disponible en: http://ww w.deusto-publicaciones.es/ud/openaccess/forum/pdfs_forum/forum06.pdf

QUIROZ-MONSALVO, AROLDO, Manual Derecho de Infancia y Adolescencia. Aspectos sustanciales y procesales (2a ed., Librería Ediciones del Profesional, Bogotá, 2009).

\section{Colaboración en obras colectivas}

ALARCÓN-PALACIO, YADIRA ELENA \& HOYOS-ROJAS, LUIS MIGUEL, El Estado de cosas inconstitucional en el desplazamiento forzado y su incidencia en el derecho fundamental de la infancia y la adolescencia a tener una familia en Colombia, en La Constitución 20 años después. Visiones desde la teoría y la práctica constitucional, 695-729 (HERNANDO YEPES-ARCILA \& VANESSA SUELT-COCK, editores académicos, Editorial Pontificia Universidad Javeriana, Konrad Adenauer Stiftung \& Grupo Editorial Ibáñez, Bogotá, 2011).

\section{Revistas}

ALARCÓN-PALACIO, YADIRA, Constitucionalismo y garantismo en los derechos de la infancia y la adolescencia en Colombia, 60 Vniversitas, 122, 363-394 (2011). Disponible en: http://revistas.javeriana.edu.co/index.php/ vnijuri/article/view/14348

RAMÍREZ-BARBOSA, PAULA ANDREA, El reclutamiento de menores en el marco del conflicto armado colombiano. Aproximación a la problemática, 1 Revista Penal México, 189-204 (2011). En: http://rabida.uhu.e s/dspace/bitstream/handle/10272/14197/el_reclutamiento_de_menores.pdf?sequence $=2$

HIERRO SÁNCHEZ-PESCADOR, LIBORIO L., ¿Tienen los niños derechos? Comentario a la Convención sobre los Derechos del Niño, 294 Revista de Educación, 221-233 (1991). Disponible en: https://www.mecd.gob.es/d ctm/revista-de-educacion/articulosre294/re29411.pdf?documentId=0901e72b813577d8

LIEBEL, MANFRED, Cien años de la Declaración de los Derechos del Niño y la Niña de Moscú. Una memoria, 2 Sociedad e Infancias, 329-332 (2018). http://dx.doi.org/10.5209/SOCI.60602. Disponible en: http://revistas. ucm.es/index.php/SOCI/article/view/60602/4564456548143

\section{Tesis}

TOLEDO-PERDOMO, JOSÉ FERNANDO, Criterios de la sala de asuntos preliminares de la Corte Penal Internacional para la admisión de una situación (tesis de Maestría en Derecho Procesal, Universidad de Medellín, Medellín, 2013).Disponible en: https://repository.udem.edu.co/bitstream/handle/11407/2218/T_MDPC_1 4.pdf?sequence $=1$

\section{Informes, reportes}

ELIASSON, NILS (Suecia), Informe sobre su segundo periodo de sesiones del Grupo de Trabajo encargado de elaborar un proyecto de protocolo facultativo de la Convención sobre los Derechos del Niño relativo a la participación de niños en los conflictos armados, E/CN.4/1996/102, 21 de marzo de 1996. Disponible en: http://ap.ohchr.org/documents 
/alldocs.aspx?doc_id=560, https://documents-dds-ny.un.org/doc/UNDOC/GEN/G96/117/69/PDF/G961 1769.pdf?OpenElement

\section{Normativa colombiana}

Colombia, Acto Legislativo 2 de 2015, por medio del cual se adopta una reforma de equilibrio de poderes y reajuste institucional y se dictan otras disposiciones. 49.560 Diario Oficial, 1 de julio de 2015. Disponible en: http://ww w.secretariasenado.gov.co/senado/basedoc/acto_legislativo_02_2015.html

Colombia, Acto Legislativo 1, 7 de julio de 2016, por medio del cual se establecen instrumentos jurídicos para facilitar y asegurar la implementación y el desarrollo normativo del Acuerdo final para la terminación del conflicto y la construcción de una paz estable y duradera. Disponible en: http://es.presidencia.gov.co/normativa/normativa/ ACTO\%20LEGISLATIVO\%2001\%20DEL\%207\%20DE\%20JULIO\%20DE\%202016.pdf

Colombia, Acto Legislativo 1, 4 de abril de 2017, por medio del cual se crea un título de disposiciones transitorias de la Constitución para la terminación del conflicto armado y la construcción de una paz estable y duradera y se dictan otras disposiciones. Disponible en: http://es.presidencia.gov.co/normativa/normativa/ACTO\%20LEG ISLATIVO\%20N\%C2\%B0\%2001\%20DE\%204\%20DE\%20ABRIL\%20DE\%202017.pdf

Colombia, Constitución Política [Const], 5 de agosto de 1886. Disponible en: http://www.suin-juriscol.gov.co/view Document.asp?id $=1826862$

Colombia, Constitución Política [Const], 7 de julio de 1991, versión corregida de la Constitución Política de Colombia, 116 Gaceta Constitucional, 20 de julio de 1991. Disponible en: http://www.secretariasenado.gov.co /index.php/constitucion-politica

Colombia, Decreto 2737 de 1989, Código del Menor. 39.080 Diario Oficial, 27 de noviembre de 1989. Disponible en: https://www.icbf.gov.co/cargues/avance/docs/codigo_menor.htm

Colombia, Decreto 2027 de 2016, de 7 de diciembre, por el cual se crea el Consejo Nacional de Reincorporación. Disponible en: http://es.presidencia.gov.co/normativa/normativa/DECRETO\%202027\%20DEL\%2007\%20 DE\%20DICIEMBRE\%20DE\%202016.pdf

Colombia, Decreto 671 de 2017, por el cual se modifica la Ley 1448 de 2011, en lo relacionado con la certificación de desvinculación de menores en caso de acuerdos de paz y se dictan otras disposiciones. 50.215 Diario Oficial, 25 de abril de 2017. Disponible en: http://www.secretariasenado.gov.co/senado/basedoc/decreto_0671_2017.html

Colombia, Ley 12 de 1991, por medio de la cual se aprueba la Convención sobre los Derechos del Niño, adoptada por la Asamblea General de las Naciones Unidas el 20 de noviembre de 1989. 39.640 Diario Oficial, 22 de enero de 1991. Disponible en: https://www.unidadvictimas.gov.co/sites/default/files/documentosbiblioteca/ley-12-de1991.pdf

Colombia, Ley 387 de 1997, por la cual se adoptan medidas para la prevención del desplazamiento forzado; la atención, protección, consolidación y estabilización socioeconómica de los desplazados internos por la violencia en la República de Colombia. 43.091 Diario Oficial, 24 de julio de 1997. Disponible en: http://www.secretariasena do.gov.co/senado/basedoc/ley_0418_1997.html

Colombia, Ley 418 de 1997, por la cual se consagran unos instrumentos para la búsqueda de la convivencia, la eficacia de la justicia y se dictan otras disposiciones. 43.201 Diario Oficial, 26 de diciembre de 1997. Disponible en: htt p://www.secretariasenado.gov.co/senado/basedoc/ley_0418_1997.html

Colombia, Ley 599 de 2000, por la cual se expide el Código Penal. 44.097 Diario Oficial, 24 de julio de 2000. Disponible en: http://www.secretariasenado.gov.co/senado/basedoc/ley_0599_2000.html

Colombia, Ley 742 de 2002, por medio de la cual se aprueba el Estatuto de Roma de la Corte Penal Internacional, hecho en Roma, el día diecisiete (17) de julio de mil novecientos noventa y ocho (1998). 44.826 Diario Oficial, 7 de junio de 2002. Disponible en: http://www.secretariasenado.gov.co/senado/basedoc/ley_0742_2002.html

Colombia, Ley 765 de 2002, por medio de la cual se aprueba el Protocolo Facultativo de la Convención sobre los Derechos del Niño relativo a la venta de niños, la prostitución infantil y la utilización de los niños en la 
pornografía, adoptado en Nueva York, el veinticinco (25) de mayo de dos mil (2000). 44.889 Diario Oficial, 5 de agosto de 2002. Disponible en: http://www.secretariasenado.gov.co/senado/basedoc/ley_0765_2002.html

Colombia, Ley 833 de 2003, por medio de la cual se aprueba el Protocolo Facultativo de la Convención sobre los Derechos del Niño relativo a la participación de niños en los conflictos armados, adoptado en Nueva York, el veinticinco (25) de mayo de dos mil (2000). 45.248 Diario Oficial, 14 de julio de 2003. Disponible en: http://w ww.secretariasenado.gov.co/senado/basedoc/ley_0833_2003.html

Colombia, Ley 890 de 2004, por la cual se modifica y adiciona el Código Penal. 45.602 Diario Oficial, 7 de julio de 2004. Disponible en: http://www.secretariasenado.gov.co/senado/basedoc/ley_0890_2004.html

Colombia, Ley 975 de 2005, por la cual se dictan disposiciones para la reincorporación de miembros de grupos armados organizados al margen de la ley, que contribuyan de manera efectiva a la consecución de la paz nacional y se dictan otras disposiciones para acuerdos humanitarios. 45.980 Diario Oficial, 25 de julio de 2005. Disponible en: http ://www.secretariasenado.gov.co/senado/basedoc/ley_0975_2005.html

Colombia, Ley 1098 de 2006, por la cual se expide el Código de la Infancia y la Adolescencia. 46.446 Diario Oficial, 8 de noviembre de 2006. Disponible en: http://www.secretariasenado.gov.co/senado/basedoc/ley_1098_2006.html

Colombia, Ley 1421 de 2010, por medio de la cual se prorroga la Ley 418 de 1997, prorrogada y modificada por las Leyes 548 de 1999, 782 de 2002 y 1106 de 2006. 47.930 Diario Oficial, 21 de diciembre de 2010. Disponible en: http://www.secretariasenado.gov.co/senado/basedoc/ley_1421_2010.html

Colombia, Ley 1448 de 2011, por la cual se dictan medidas de atención, asistencia y reparación integral a las víctimas del conflicto armado interno y se dictan otras disposiciones. 48.096 Diario Oficial, 10 de junio de 2011. Disponible en: http://www.secretariasenado.gov.co/senado/basedoc/ley_1448_2011.html

Colombia, Ley 1820 de 2016, por medio de la cual se dictan disposiciones sobre amnistía, indulto y tratamientos penales especiales y otras disposiciones. 50.102 Diario Oficial, 30 de diciembre de 2016. Disponible en: http:// www.secretariasenado.gov.co/senado/basedoc/ley_1820_2016.html

Colombia, Resolución 1525 de 2016, del Instituto Colombiano de Bienestar Familiar, ICBF, 23 de febrero de 2016, por la cual se aprueba el lineamiento técnico de las modalidades del programa de atención especializada para el restablecimiento de derechos a niños, niñas y adolescentes víctimas de reclutamiento ilícito, que se han desvinculado de grupos armados organizados al margen de la ley y contribución al proceso de reparación integral. 49.799 Diario Oficial, 27 de febrero de 2016. Disponible en: https://www.icbf.gov.co/cargues/avance/docs/re solucion_icbf_1525_2016.htm

\section{Tratados, convenios, acuerdos, resoluciones internacionales}

ORGANIZACIÓN DE ESTADOS AMERICANOS, OEA, Convención Americana sobre Derechos Humanos, San José, Costa Rica, 7 al 22 de noviembre de 1969. Disponible en: https://www.oas.org/dil/esp/tratados_b-32_co nvencion_americana_sobre_derechos_humanos.htm

ORGANIZACIÓN DE ESTADOS AMERICANOS, OEA, Declaración Americana de los Derechos y Deberes del Hombre, aprobada en la Novena Conferencia Internacional Americana, Bogotá, 1948. Disponible en: http://w ww.oas.org/es/cidh/mandato/Basicos/declaracion.asp

ORGANIZACIÓN DE ESTADOS AMERICANOS, OEA, Protocolo adicional a la Convención Americana sobre Derechos Humanos, en materia de derechos económicos, sociales y culturales - Protocolo de San Salvador. Disponible en: https://www.oas.org/juridico/spanish/tratados/a-52.html

ORGANIZACIÓN DE NACIONES UNIDAS, ASAMBLEA GENERAL, Pacto Internacional de Derechos Civiles y Políticos, adoptado por la Asamblea General en su resolución 2200 A (XXI), 16 de diciembre de 1966. Disponible en: https://www.ohchr.org/sp/professionalinterest/pages/ccpr.aspx

ORGANIZACIÓN DE NACIONES UNIDAS, ASAMBLEA GENERAL, Protocolo Facultativo de la Convención sobre los Derechos del Niño relativo a la participación de los niños en conflictos armados, Asamblea General, Resolución A/RES/54/263, 25 de mayo de 2000; entró en vigencia el 12 de febrero de 2002. Disponible en: ht tps://www.ohchr.org/sp/professionalinterest/pages/opaccrc.aspx 
ORGANIZACIÓN DE NACIONES UNIDAS, CONSEJO DE SEGURIDAD, Resolución 1612 de 2005, Mecanismo de defensa para los niños, niñas y adolescentes en el marco del conflicto armado, aprobada por el Consejo de Seguridad en su 5235 sesión, 26 de julio de 2005. Disponible en: https://www.acnur.org/fileadmi n/Documentos/BDL/2005/3635.pdf

\section{Jurisprudencia}

Colombia, Corte Constitucional, Auto A251-08, 6 de octubre de 2008, magistrado ponente Manuel José CepedaEspinosa. Disponible en: http://www.corteconstitucional.gov.co/relatoria/autos/2008/a251-08.htm

Colombia, Corte Constitucional, Sentencia C-291-07, 25 de abril de 2007, magistrado ponente Manuel José CepedaEspinosa. Disponible en: http://www.corteconstitucional.gov.co/RELATORIA/2007/C-291-07.htm

Colombia, Corte Constitucional, Sentencia C-253A-12, 29 de marzo de 2012, magistrado ponente Gabriel Eduardo Mendoza-Martelo. Disponible en: http://www.corteconstitucional.gov.co/relatoria/2012/C-253A-12.htm

Colombia, Corte Constitucional, Sentencia C-069-16, 18 de febrero de 2016, magistrado ponente Luis Guillermo Guerrero-Pérez. Disponible en: http://www.corteconstitucional.gov.co/relatoria/2016/c-069-16.htm

Colombia, Corte Constitucional, Sentencia C-541-17, 24 de agosto de 2017, magistrado ponente Iván Humberto Escrucería-Mayolo. Disponible en: http://www.corteconstitucional.gov.co/relatoria/2017/c-541-17.htm

Colombia, Corte Constitucional, Sentencia C-007-18, 1 de marzo de 2018, magistrada ponente Diana Fajardo-Rivera. Disponible en: http://www.corteconstitucional.gov.co/relatoria/2018/c-007-18.htm

Colombia, Corte Constitucional, Sentencia T-025-04, 22 de enero de 2004, magistrado ponente Manuel José CepedaEspinosa. Disponible en: http://www.corteconstitucional.gov.co/relatoria/2004/t-025-04.htm

\section{Fuentes oficiales nacionales e internacionales}

COALICIÓN CONTRA LA VINCULACIÓN DE NIÑOS, NIÑAS Y JÓVENES AL CONFLICTO ARMADO EN COLOMBIA, COALICO \& OTROS, Informe alterno al informe del Estado colombiano sobre el cumplimiento del Protocolo Facultativo Relativo a la Participación de Niños en los Conflictos Armados (Coalico \& otros, Bogotá, 2009). Disponible en: http://coljuristas.org/documentos/libros_e_informes/informe_altern o_ninos.pdf

COALICIÓN ESPAÑOLA PARA ACABAR CON LA UTILIZACIÓN DE NIÑOS SOLDADO, Niños soldado. Informe global 2004, Edición resumida (Coalición en España, Amnistía Internacional Sección Española \& Save the Children, Madrid, 2004). Disponible en: https://www.entreculturas.org/files/documentos/biblioteca/Me nores_Soldado_Informe_Global_2004.pdf

Colombia, CENTRO NACIONAL DE MEMORIA HISTÓRICA, CNMH, Una guerra sin edad. Informe nacional de reclutamiento y utilización de niños, niñas y adolescentes en el conflicto armado colombiano (Centro Nacional de Memoria Histórica, CNMH Bogotá, 2017). Disponible en: http://www.centrodememoriahistorica.gov.co/ descargas/informes2018/una_guerra-sin-edad.pdf

Colombia, CONSEJO NACIONAL DE REINCORPORACIÓN, CNR, Lineamientos del Consejo Nacional de Reincorporación (CNR) para el Programa Integral Especial de Restitución de los Derechos de los Niños, Niñas y Adolescentes que salgan de las FARC-EP, Camino Diferencial de Vida, CDV - Programa para Niños, Niñas, Adolescentes y Jóvenes (Consejo Nacional de Reincorporación, CNR, Bogotá, 5 de febrero de 2018). Disponible en: http://www.derechoshumanos.gov.co/observatorio/publicaciones/Documents/2018/180309-lineamiento s-reclutamiento.pdf

Colombia, GOBIERNO NACIONAL \& FARC-EP, Acuerdo final para la terminación del conflicto y la construcción de una paz estable y duradera (2016). Disponible en: http://www.altocomisionadoparalapaz.gov.co/procesos-y -conversaciones/Documentos\%20compartidos/24-11-2016NuevoAcuerdoFinal.pdf

Colombia, INSTITUTO COLOMBIANO DE BIENESTAR FAMILIAR, ICBF, ORGANIZACIÓN INTERNACIONAL PARA LAS MIGRACIONES, OIM \& FONDO DE LAS NACIONES UNIDAS 
PARA LA INFANCIA, UNICEF, Impacto del conflicto armado en el estado psicosocial de niños, niñas y adolescentes (Convenio NAJ-661, Bogotá, noviembre de 2014). Disponible en: https://repository.oim.org.co/h andle $/ 20.500 .11788 / 541$ ?locale-attribute $=$ en

FONDO DE LAS NACIONES UNIDAS PARA LA INFANCIA, UNICEF, COALICIÓN PARA ACABAR CON LA UTILIZACIÓN DE NIÑOS SOLDADOS, Guia del Protocolo facultativo sobre la participación de niños y niñas en los conflictos armados (FONDO DE LAS NACIONES UNIDAS PARA LA INFANCIA, UNICEF, Nueva York, mayo de 2014). Disponible en: https://www.unicef.org/spanish/publications/files/SP ANISHnw.pdf

FONDO DE LAS NACIONES UNIDAS PARA LA INFANCIA, UNICEF, Los Principios de Paris (2007). Disponible en: https://www.unicef.org/protection/Paris_Principles_SP.pdf

FONDO DE LAS NACIONES UNIDAS PARA LA INFANCIA, UNICEF Colombia, Convención sobre los derechos de los niños y las niñas (2005). Disponible en: https://www.unicef.org/colombia/pdf/CDNparte1.pdf

NACIONES UNIDAS, Observaciones finales del Comité de los Derechos del Niño: Colombia, CRC/C/15/Add.137 (Concluding Observations/Comments), Comité de los Derechos del Niño, 25 período de sesiones (16 de octubre de 2000). Disponible en: https://www.acnur.org/fileadmin/Documentos/BDL/2002/1540.pdf?file=fileadmi n/Documentos/BDL/2002/1540

NACIONES UNIDAS, ASAMBLEA GENERAL, Las repercusiones de los conflictos armados sobre los niños, A/51/306. Informe de la experta del Secretario General, Sra. Graça Machel, presentado en virtud de la resolución 48/157 (1996). Disponible en: https://www.acnur.org/fileadmin/Documentos/BDL/2008/6260.pdf

ORGANIZACIÓN DE LAS NACIONES UNIDAS, ONU, Estatuto de Roma de la Corte Penal Internacional, A/ CONF.183/9 (17 de julio de 1998). Disponible en: https://www.oas.org/36ag/espanol/doc_referencia/estatu to_roma.pdf

ORGANIZACIÓN INTERNACIONAL DEL TRABAJO - OIT, C182 - Convenio sobre las peoresformas de trabajo infantil (1999) (núm. 182), Convenio sobre la prohibición de las peores formas de trabajo infantil y la acción inmediata para su eliminación (en vigor: 19 de noviembre de 2000). Disponible en: https://www.ilo.org/dyn/n ormlex/es/f?p=NORMLEXPUB:12100:0::NO::P12100_ILO_CODE:C182

\section{Otras publicaciones electrónicas}

http://menoresguerra.blogspot.com/2008/06/plan-de-las-farc-para-reclutar-menores.html

http://www.altocomisionadoparalapaz.gov.co/mesadeconversaciones/PDF/comunicado-conjunto-70-15-de-mayode-2016-1463349969.pdf

http://www.cruzroja.es/principal/documents/1750782/1852289/protocolo_adicional_II_conv_ginebra_1949.p df/110be401-0cc3-4837-9cf1-0fd731dcca87

http://www.un.org/es/events/childrenday/pdf/derechos.pd

http://www.un.org/es/universal-declaration-human-rights/

https://www.elespectador.com/impreso/nacional/articuloimpreso-alerta-reclutamiento-de-menores

https://www.semana.com/on-line/articulo/de-raspachines-guerrilleros-asi-reclutan-menores-catatumbo/92816-3

https://www.unicef.org/colombia/pdf/crecer1.pdf

https://www.unicef.org/spanish/rightsite/sowc/pdfs/panels/SOWC\%20all\%20panels\%20SP.pdf

\section{Notas}

* Artículo de investigación

1 FONDO DE LAS NACIONES UNIDAS PARA LA INFANCIA, UNICEF, COALICIÓN PARA ACABAR CON LA UTILIZACIÓN DE NIÑOS SOLDADOS, Guia del Protocolo facultativo sobre la participación de niños y niñas en los conflictos armados, 14 (FONDO DE LAS NACIONES UNIDAS PARA LA INFANCIA, UNICEF, Nueva York, mayo de 2014). 
2 COALICIÓN ESPAÑOLA PARA ACABAR CON LA UTILIZACIÓN DE NIÑOS SOLDADO, Niños soldado. Informe global 2004, Edición resumida, 6 (Coalición en España, Amnistía Internacional Sección Española \& Save the Children, Madrid, 2004).

\section{FONDO DE LAS NACIONES UNIDAS PARA LA INFANCIA, UNICEF, COALICIÓN PARA ACABAR CON LA UTILIZACIÓN DE NIÑOS SOLDADOS, Guia del Protocolo Facultativo..., 3.}

4 El informe de 1996 sostiene que en una serie de 24 estudios de casos sobre la utilización de los niños como soldados, que comprenden conflictos ocurridos durante los 30 años anteriores, se ve que tanto los ejércitos gubernamentales como los ejércitos de rebeldes de todo el mundo han reclutado decenas de miles de niños. La mayoría de ellos son adolescentes, aunque muchos niños soldados tienen 10 años de edad o menos. Si bien la mayoría son varones, también reclutan niñas. Los niños que más frecuentemente se convierten en soldados son los que proceden de orígenes empobrecidos y marginados o los que han quedado separados de su familia. NACIONES UNIDAS, ASAMBLEA GENERAL, Las repercusiones de los conflictos armados sobre los niños, A/51/306. Informe de la experta del Secretario General, Sra. Graça Machel, presentado en virtud de la resolución 48/157, 17 (1996), que cita a RACHEL BRETT, MARGARET MACCALLIN \& RHONDA O'SHEA, Children: The Invisible Soldiers, 88 (QUAKER UNITED NATIONS OFFICE and the INTERNATIONAL CATHOLIC CHILD BUREAU, Geneva, April, 1996).

5 Colombia, INSTITUTO COLOMBIANO DE BIENESTAR FAMILIAR, ICBF, ORGANIZACIÓN INTERNACIONAL PARA LAS MIGRACIONES, OIM \& FONDO DE LAS NACIONES UNIDAS PARA LA INFANCIA, UNICEF, Impacto del conflicto armado en el estado psicosocial de niños, niñas y adolescentes, 36 (Convenio NAJ-661, Bogotá, noviembre de 2014).

$6 \quad I d ., 36-37$.

$7 \quad I d ., 63$.

$8 \quad I d ., 83$.

$9 \quad I d ., 83-84$.

10 Los primeros datos que hemos encontrado provienen de finales de la Primera Guerra Mundial. En el contexto de la Revolución Rusa, de octubre de 1917, surgió una Declaración sobre los Derechos de los Niños y las Niñas que representa la existencia de una corriente emancipadora en la historia de los derechos de la niñez. Esta Declaración iba mucho más lejos de todo lo que hasta aquel momento se había entendido como derechos de la infancia en Europa y más allá, y todavía hoy puede proporcionar algún estímulo. Según MANFRED LIEBEL: "La Declaración surgió a pocos meses del estallido de la Revolución de Octubre, en la primera Conferencia de Organizaciones Culturales y Educativas Proletarias (Moscú-Prolet'cult) (una organización de trabajadores culturales que incluía a artistas, así como a educadores y a científicos) celebrada del 23 al 28 de febrero de 1918 en Moscú... La mencionada Declaración nunca llegó a ser oficialmente reconocida, ya que el Comité para la Educación de los Niños, Niñas y Jóvenes — creado en la misma conferencia de Prolet'cult— la había rechazado, calificándola de \#inaceptable\# porque \#habla con la lengua del derecho natural que es refutado por el marxismo y que tiene características anticolectivas\#". MANFRED LIEBEL, Cien años de la Declaración de los Derechos del Niño y la Niña de Moscú. Una memoria, 2 Sociedad e Infancias, 329-332, 329 (2018). h ttp://dx.doi.org/10.5209/SOCI.60602.

11 LIBORIO L. HIERRO SÁNCHEZ-PESCADOR, ¿Tienen los niños derechos? Comentario a la Convención sobre los Derechos del Niño, 294 Revista de Educación, 221-233, 228-229 (1991).

12 JAIME ORAÁ-ORAÁ \& FELIPE GÓMEZ-ISA, La Declaración Universal de los Derechos Humanos. Un breve comentario en su 50 aniversario, 11 (Publicaciones Universidad de Deusto, Bilbao, 1997).

13 NACIONES UNIDAS, Declaración Universal de Derechos Humanos. http://www.un.org/es/universal-declaration-huma n-rights/

14 MARCELA ARELLANO-VELASCO, Uso y participación de niños en conflictos armados, 47 (Editorial de la Universidad de Granada, Granada, 2008).

$15 \quad I d ., 47$.

16 LIBORIO L. HIERRO SÁNCHEZ-PESCADOR, ¿Tienen los niños derechos? Comentario a la Convención sobre los Derechos del Niño, 294 Revista de Educación, 221-233, 228-229 (1991).

17 Negrillas fuera de texto. 
18 http://www.cruzroja.es/principal/documents/1750782/1852289/protocolo_adicional_II_conv_ginebra_1949.pdf/110 be401-0cc3-4837-9cf1-0fd731dcca87

19 Convención sobre los Derechos del Niño. http://www.un.org/es/events/childrenday/pdf/derechos.pdf

20 Negrillas fuera de texto.

21 Convención sobre los Derechos del Niño. http://www.un.org/es/events/childrenday/pdf/derechos.pdf

22 Cf. NILS ELIASSON (Suecia), Informe sobre su segundo periodo de sesiones del Grupo de Trabajo encargado de elaborar un proyecto de protocolo facultativo de la Convención sobre los Derechos del Niño relativo a la participación de niños en los conflictos armados, E/CN.4/1996/102, 21 de marzo de 1996,7. FELIPE GÓMEZ-ISA, La participación de los niños en los conflictos armados (Colección Cuadernos Deusto Derechos Humanos 10, Publicaciones Universidad de Deusto, Bilbao, 2000).

23 NACIONES UNIDAS, ASAMBLEA GENERAL, Las repercusiones de los conflictos armados sobre los niños, A/51/306, 17 (1996).

24 ORGANIZACIÓN DE LAS NACIONES UNIDAS, ONU, Estatuto de Roma de la Corte Penal Internacional, A/ CONF.183/9, artículo 8.2.b.xxvi (17 de julio de 1998).

25 ORGANIZACIÓN INTERNACIONAL DEL TRABAJO - OIT, C182 - Convenio sobre las peores formas de trabajo infantil (1999) (núm. 182), Convenio sobre la prohibición de las peores formas de trabajo infantil y la acción inmediata para su eliminación, artículo 3.

26 https://www.unicef.org/spanish/rightsite/sowc/pdfs/panels/SOWC\%20all\%20panels\%20SP.pdf

27 MARCELA ARELLANO-VELASCO, Uso y participación de niños en conflictos armados, 164 (2008).

28 Cf. FELIPE GÓMEZ-ISA, La participación de los niños en los conflictos armados, 1-83, 56 (Colección Cuadernos Deusto Derechos Humanos 10, Publicaciones Universidad de Deusto, Bilbao, 2000).

$29 \quad I d$. , nota de pie de página 162.

30 JOSÉ FERNANDO TOLEDO-PERDOMO, Criterios de la sala de asuntos preliminares de la Corte Penal Internacional para la admisión de una situación, 112 (tesis de Maestría en Derecho Procesal, Universidad de Medellín, Medellín, 2013).

31 ORGANIZACIÓN DE LAS NACIONES UNIDAS [ONU], Estatuto de Roma de la Corte Penal Internacional, A/ CONF.183/9 78, artículo 8.2.b.xxvi (1998).

32 FONDO DE LAS NACIONES UNIDAS PARA LA INFANCIA, UNICEF, Los Principios de París (2007).

$33 I d$.

34 Colombia, Decreto 2737 de 1989, Código del Menor. 39.080 Diario Oficial, 27 de noviembre de 1989.

35 YADIRA ALARCÓN-PALACIO, Constitucionalismo y garantismo en los derechos de la infancia y la adolescencia en Colombia, 60 Vniversitas, 122, 363-394, 371 (2011).

36 NACIONES UNIDAS, Observaciones finales del Comité de los Derechos del Niño: Colombia, CRC/C/15/Add.137 (Concluding Observations/Comments), Comité de los Derechos del Niño, 25 período de sesiones (16 de octubre de 2000).

37 YADIRA ALARCÓN-PALACIO, Constitucionalismo y garantismo..., 60 Vniversitas, 122, 363-394, 371 (2011). Para la revisión de los antecedentes de este proceso, Cf. AROLDO QUIROZ-MONSALVO, Manual Derecho de Infancia y Adolescencia. Aspectos sustanciales y procesales, 10 ss. (2ª ed., Librería Ediciones del Profesional, Bogotá, 2009).

38 Colombia, CENTRO NACIONAL DE MEMORIA HISTÓRICA, CNMH, Una guerra sin edad. Informe nacional de reclutamiento y utilización de niños, niñas y adolescentes en el conflicto armado colombiano, 560 (Centro Nacional de Memoria Histórica, CNMH, Bogotá, 2017).

39 ORGANIZACIÓN DE NACIONES UNIDAS, ASAMBLEA GENERAL, Protocolo Facultativo de la Convención sobre los Derechos del Niño relativo a la participación de los niños en conflictos armados, Asamblea General, Resolución A/ RES/54/263, 25 de mayo de 2000; entró en vigencia el 12 de febrero de 2002. 
40 Colombia, Corte Constitucional, Sentencia C-069-16, 18 de febrero de 2016, magistrado ponente Luis Guillermo GuerreroPérez. Cf. FONDO DE LAS NACIONES UNIDAS PARA LA INFANCIA, UNICEF Colombia, Convención sobre los derechos de los niños y las niñas, 11 (2005).

41 Colombia, Corte Constitucional, Sentencia C-007-18, 1 de marzo de 2018, magistrada ponente Diana Fajardo-Rivera. Nota 373: "Aunque Colombia ratificó el instrumento el 25 de mayo de 2005, su artículo 10(2) dispone que \#el Protocolo entrará en vigor un mes después de la fecha en que se haya depositado el correspondiente instrumento de ratificación o de adhesión\#. De igual manera, aunque este Protocolo data del 25 de mayo de 2000, el artículo 10(1) ejusdem establece que el mismo entraría \#en vigor tres meses después de la fecha en que haya sido depositado el décimo instrumento de ratificación o de adhesión\#. Así, Nueva Zelanda fue el décimo Estado en obligarse por el tratado, depositando el respectivo instrumento el 12 de noviembre de 2001, entrando en vigor el Protocolo el 12 de febrero de 2002".

42 Colombia, CENTRO NACIONAL DE MEMORIA HISTÓRICA, CNMH, Una guerra sin edad..., nota 239 (2017), que cita a ÁLVARO VILLARRAGA-SARMIENTO (2013) y a CARLOS OTÁLORA-CASTAÑEDA \& MARÍA FERNANDA BERMEO (2013).

43 Id. Negrita fuera de texto. La norma reza lo siguiente: Artículo 124. Disposición de Transición. No obstante, lo dispuesto en los párrafos 1 y 2 del artículo 12, un Estado, al hacerse parte en el presente Estatuto, podrá declarar que, durante un período de siete años contados a partir de la fecha en que el Estatuto entre en vigor a su respecto, no aceptará la competencia de la Corte sobre la categoría de crímenes a que se hace referencia en el artículo 8 cuando se denuncie la comisión de uno de esos crímenes por sus nacionales o en su territorio. La declaración formulada de conformidad con el presente artículo podrá ser retirada en cualquier momento. Lo dispuesto en el presente artículo será reconsiderado en la Conferencia de Revisión que se convoque de conformidad con el párrafo 1 del artículo 123.

44 Colombia, CENTRO NACIONAL DE MEMORIA HISTÓRICA, CNMH, Una guerra sin edad..., 562-563 (2017).

45 Colombia, Corte Constitucional, Sentencia T-025-04, 22 de enero de 2004, magistrado ponente Manuel José CepedaEspinosa.

46 Colombia, Ley 387 de 1997, por la cual se adoptan medidas para la prevención del desplazamiento forzado; la atención, protección, consolidación y estabilización socioeconómica de los desplazados internos por la violencia en la República de Colombia. 43.091 Diario Oficial, 24 de julio de 1997.

47 YADIRA ELENA ALARCÓN-PALACIO \& LUIS MIGUEL HOYOS-ROJAS, El Estado de cosas inconstitucional en el desplazamiento forzado y su incidencia en el derecho fundamental de la infancia y la adolescencia a tener una familia en Colombia, en La constitución 20 años después. Visiones desde la teoría y la práctica constitucional, 695-730 (HERNANDO YEPES-ARCILA \& VANESSA SUELT-COCK, editores académicos, Editorial Pontificia Universidad Javeriana, Konrad Adenauer Stiftung \& Grupo Editorial Ibáñez, Bogotá, 2011).

48 Colombia, Corte Constitucional, Auto A251-08, 6 de octubre de 2008, magistrado ponente Manuel José CepedaEspinosa.

49 Id.

50 Colombia, Constitución Política [Const], 7 de julio de 1991, versión corregida de la Constitución Política de Colombia, 116 Gaceta Constitucional, 20 de julio de 1991, artículo 44.

51 Colombia, Corte Constitucional, Auto A251-08.

52 Colombia, Corte Constitucional, Sentencia C-291-07, 25 de abril de 2007, magistrado ponente Manuel José CepedaEspinosa. Cf. YADIRA ELENA ALARCÓN-PALACIO, El Estado de cosas inconstitucional en el desplazamiento forzado y..., 695-730, $710(2011)$.

53 Id. Cf. YADIRA ELENA ALARCÓN-PALACIO, El Estado de cosas inconstitucional en el desplazamiento forzado y..., 695-730, $711(2011)$.

54 Colombia, CENTRO NACIONAL DE MEMORIA HISTÓRICA, CNMH, Una guerra sin edad... (2017). ORGANIZACIÓN DE NACIONES UNIDAS, CONSEJO DE SEGURIDAD, Resolución 1612 de 2005, Mecanismo de defensa para los niños, niñas y adolescentes en el marco del conflicto armado, aprobada por el Consejo de Seguridad en su 5235 sesión, 26 de julio de 2005. 
55 Cf. YADIRA ALARCÓN-PALACIO, Constitucionalismo y garantismo en los derechos de la infancia y la adolescencia en Colombia, 60 Vniversitas, 122, 363-394 (2011).

56 Colombia, CONSEJO NACIONAL DE REINCORPORACIÓN, CNR, Lineamientos del Consejo Nacional de Reincorporación (CNR) para el Programa Integral Especial de Restitución de los Derechos de los Niños, Niñasy Adolescentes que salgan de las FARC-EP, Camino Diferencial de Vida, CDV - Programa para Niños, Niñas, Adolescentes y Jóvenes, 8-9 (Consejo Nacional de Reincorporación, CNR, Bogotá, 5 de febrero de 2018).

57 https://www.elespectador.com/impreso/nacional/articuloimpreso-alerta-reclutamiento-de-menores. PAULA ANDREA RAMÍREZ-BARBOSA, El reclutamiento de menores en el marco del conficto armado colombiano. Aproximación a la problemática, 1 Revista Penal México, 189-204 (2011).

58 http://menoresguerra.blogspot.com/2008/06/plan-de-las-farc-para-reclutar-menores.html. PAULA ANDREA RAMÍREZ-BARBOSA, El reclutamiento de menores en el marco... (2011).

59 https://www.semana.com/on-line/articulo/de-raspachines-guerrilleros-asi-reclutan-menores-catatumbo/92816-3. PAULA ANDREA RAMÍREZ-BARBOSA, El reclutamiento de menores en el marco... (2011).

60 Colombia, CENTRO NACIONAL DE MEMORIA HISTÓRICA, CNMH, Una guerra sin edad..., 121 (2017).

61 Colombia, CENTRO NACIONAL DE MEMORIA HISTÓRICA, CNMH, Una guerra sin edad..., 122 (2017).

62 Colombia, CENTRO NACIONAL DE MEMORIA HISTÓRICA, CNMH, Una guerra sin edad... (2017).

63 Colombia, GOBIERNO NACIONAL \& FARC-EP, Acuerdo final para la terminación del conflicto y la construcción de una paz estable y duradera (2016).

64 Id.

65 Colombia, Corte Constitucional, Sentencia C-541-17, 24 de agosto de 2017, magistrado ponente Iván Humberto Escrucería-Mayolo.

66 Id.

67 El artículo 3 señala: "Víctimas. Se consideran víctimas, para los efectos de esta ley, aquellas personas que individual o colectivamente hayan sufrido un daño por hechos ocurridos a partir del 1 de enero de 1985, como consecuencia de infracciones al Derecho Internacional Humanitario o de violaciones graves y manifiestas a las normas internacionales de Derechos Humanos, ocurridas con ocasión del conflicto armado interno. También son víctimas el cónyuge, compañero o compañera permanente, parejas del mismo sexo y familiar en primer grado de consanguinidad, primero civil de la víctima directa, cuando a esta se le hubiere dado muerte o estuviere desaparecida. A falta de estas, lo serán los que se encuentren en el segundo grado de consanguinidad ascendente".

68 Colombia, Corte Constitucional, Sentencia C-253A-12, 29 de marzo de 2012, magistrado ponente Gabriel Eduardo Mendoza-Martelo.

69 Colombia, Corte Constitucional, Sentencia C-541-17, 24 de agosto de 2017, magistrado ponente Iván Humberto Escrucería-Mayolo.

70 Colombia, CONSEJO NACIONAL DE REINCORPORACIÓN, CNR, Lineamientos del Consejo Nacional de Reincorporación... (5 de febrero de 2018).

71 Colombia, Corte Constitucional, Sentencia C-541-17, 24 de agosto de 2017, magistrado ponente Iván Humberto Escrucería-Mayolo.

72 Id. La Corte entiende que el artículo 1 del Decreto Ley 891 de 2017 parte del principio de la buena fe, de la garantía prevalente de los derechos de los menores y del derecho a la reparación integral y el restablecimiento de derechos de los menores víctimas del delito de reclutamiento ilícito y, a partir de ello, reconoce un tratamiento especial para esos casos en los que, a pesar de la presunción de minoría de edad, se demuestra que la persona es mayor de edad. En efecto, como se desprende del contenido de la disposición, este tratamiento especial consiste justamente en permitir que, a pesar de la verificación formal de la edad de quien fuera presumido menor, este no deba salir de forma abrupta de los lugares transitorios de acogida y abandonar el proceso de desvinculación, sino que pueda permanecer allí mientras es ubicado en la oferta institucional, de conformidad con el programa Camino Diferencial de Vida en su condición de mayor de edad. Para ello, en garantía de los derechos de los menores que permanecen en esos lugares, la misma 
norma dispone que el ICBF debe ajustar sus lineamientos técnicos y los estándares correspondientes que apoyen el cumplimiento de la medida.

73 Colombia, Corte Constitucional, Sentencia C-069-16, 18 de febrero de 2016, magistrado ponente Luis Guillermo GuerreroPérez.

74 Consagrado en el artículo 2 de la Convención sobre los Derechos del Niño de 1989. Principio 15 (negrillas fuera de texto).

75 Cf. Documento Principios de París, numeral 3 y Compromisos de París. Compromiso 16.

76 Colombia, Corte Constitucional, Sentencia C-069-16, 18 de febrero de 2016, magistrado ponente Luis Guillermo GuerreroPérez.

77 Negrilla fuera de texto.

78 Negrillas fuera de texto.

79 Citas suprimidas.

80 Negrillas fuera del texto.

81 Colombia, CENTRO NACIONAL DE MEMORIA HISTÓRICA, CNMH, Una guerra sin edad..., 560 (2017).

82 Colombia, Corte Constitucional, Sentencia C-541-17, 24 de agosto de 2017, magistrado ponente Iván Humberto Escrucería-Mayolo.

83 COALICIÓN CONTRA LA VINCULACIÓN DE NIÑOS, NIÑAS Y JÓVENES AL CONFLICTO ARMADO EN COLOMBIA, COALICO \& OTROS, Informe alterno al informe del Estado colombiano sobre el cumplimiento del Protocolo Facultativo Relativo a la Participación de Niños en los Conflictos Armados, 82 (Coalico \& otros, Bogotá, 2009).

\section{Licencia Creative Commons CC BY 4.0}

Para citar este articulo / To cite this article: ALARCÓN-PALACIO, YADIRA, Reclutamiento forzado de niños y niñas (abduction) en el conflicto armado colombiano: los menores de 18 años como víctimas con protección especial reforzada en el DIH y DIDH, 138 Vniversitas (2019). https://doi:10.11144/Javeriana.vj138.rfnn 